\title{
The relationship between aging and carcinogenesis: a critical appraisal
}

\author{
Vladimir N. Anisimov* \\ Department of Carcinogenesis and Oncogerontology, N.N. Petrov Research Institute of Oncology, Pesochny-2, 68 Leningradskaya St., \\ St. Petersburg 197758, Russia
}

Accepted 11 September 2002

\begin{abstract}
Contents

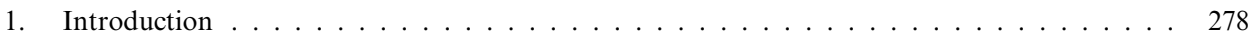

2. Age-related increase in spontaneous tumor development . . . . . . . . . . . . . 278

3. Is the susceptibility to carcinogenesis similar in different tissues at different age . . . . . . 279

4. Aging and multi-stage carcinogenesis . . . . . . . . . . . . . . . . . . . 280

5. Cellular senescence and carcinogenesis . . . . . . . . . . . . . . . . . . 284

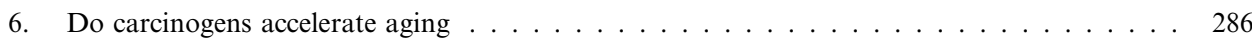

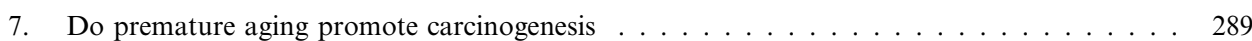

8. Effect of genetic modifications of aging on carcinogenesis _ . . . . . . . . . . . . 290

9. Oxidative stress in aging and carcinogenesis . . . . . . . . . . . . . . . . . . . 293

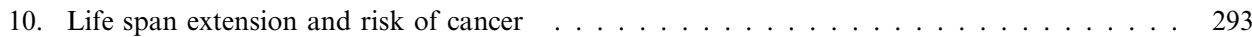

11. Conclusions . . . . . . . . . . . . . . . . . . . . . . . . 297

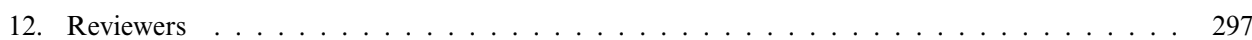

Acknowledgements . . . . . . . . . . . . . . . . . . . . . . . . . . 297

References . . . . . . . . . . . . . . . . . . . . . . . . . 297

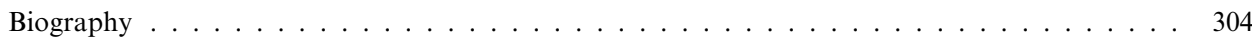

\begin{abstract}
The incidence of cancer increases with age in humans and in laboratory animals alike. There are different patterns of age-related distribution of tumors in different organs and tissues. Aging may increase or decrease the susceptibility of various tissues to initiation of carcinogenesis and usually facilitates promotion and progression of carcinogenesis. Aging may predispose to cancer by several mechanisms: (1) tissue accumulation of cells in late stages of carcinogenesis; (2) alterations in homeostasis, in particular, alterations in immune and endocrine system and (3) telomere instability linking aging and increased cancer risk. Increased susceptibility to the effects of tumor promoters is found both in aged animals and aged humans, as predicted by the multistage model of carcinogenesis. Available evidence supporting the relevance of replicative senescence of human cells and telomere biology to human cancer seems quite strong, however, the evidence linking cellular senescence to human aging is controversial and required additional stuidies. Data on the acceleration of aging by carcinogenic agents as well as on increased cancer risk in patients with
\end{abstract}

* Tel.: +7-812-596-8607; fax: +7-812-596-8947.

E-mail address: aging@mail.ru (V.N. Anisimov). 
premature aging are critically discussed. In genetically modified mouse models (transgenic, knockout or mutant) characterized by the aging delay, the incidence of tumors usually similar to those in controls, whereas the latent period of tumor development is increased. Practically all models of accelerated of aging in genetically modified animals show the increase in the incidence and the reduction in the latency of tumors. Strategies for cancer prevention must include not only measures to minimize exposure to exogenous carcinogenic agents, but also measures to normalize the age-related alterations in internal milieu. Life-span prolonging drugs (geroprotectors) may either postpone population aging and increase of tumor latency or decrease the mortality in long-living individuals in populations and inhibit carcinogenesis. At least some geroprotectors may increase the survival of a short-living individuals in populations but increase the incidence of malignancy.

(C) 2002 Elsevier Science Ireland Ltd. All rights reserved.

Keywords: Carcinogenesis; Aging; Susceptibility to carcinogenesis; Life span extension

\section{Introduction}

Cancer is a common cause of disability and death in the elderly: over $50 \%$ of malignant neoplasms occur in persons over $70[1,2]$. The relationship between aging and cancer is not clear: considerable controversy surrounds the mechanisms that lead to increased incidence of cancer in the aged. It is worthy to note that frequencies of specific cancers are age-specific [1,2]. Three major hypotheses have been proposed to explain the association of cancer and age. The first hypothesis holds this association is a consequence of the duration of carcinogenesis. In other words, the sequential carcinogenic steps that are required for the neoplastic transformation of normal tissues develop over several years and cancer is more likely to become manifest in older individuals by a process of natural selection $[3,4]$. In an article entitled, 'There is no such thing as aging, and cancer is not related to it,' R. Peto et al. [4] have proposed that the high prevalence of cancer in older individuals simply reflects a more prolonged exposure to carcinogens. In the estimate of these authors, the incidence of cancer is a power function of the duration of carcinogen exposure, rather than a power function of the tumor-host age. Recently J. Peto [5] claimed that the epidemiological and experimental evidence suggests that somatic ageing processes per se play little or no role in carcinogenesis. In a paper entitled 'There is no such thing as aging', R. Peto and Sir R. Doll, [6] have stressed that the fact that a wide range of adult diseases, cancer including, tend to arise in the same part of the life span is not a good evidence that they have similar underlying mechanisms, nor is it good evidence that any single, unifying change awaits discovery that could properly be called 'aging'.

The second hypothesis proposes that age-related progressive changes in the internal milieu of the organism may provide an increasingly favorable environment for the initiation of new neoplasms and for the growth of already existent, but latent malignant cells [7-16]. These mechanisms may also include proliferate senescence, as the senescent cells loses the ability to undergo apoptosis [17-19] and, as it has been suggested, produce multiple factors, which act together, to stimulate epithe- lial cells with oncogenic mutations [20]. Among specific mediators of age-dependent changes in stromal-epithelial cell interaction the cytokine interleukin-1, transforming growth factor $\beta$, keratinocyte growth factor, hepatocyte growth factor, pigmented epithelium-derived factor/early population doubling clone-1 (PEDF/EPC1), a member of the serine protease inhibitor family, are potential soluble mediators of stroma-epithelial cell interactions [21].

The third hypotesis proposes that the cancer-prone phenotype of older humans might reflect the combined effects of cumultaive mutational load, increased epigenetic gene silencing, telomere dysfunction and altered stromal milieu [14]. DePinho [14] stressed that telomere dysfunction might be leading among of several mechanisms driving epithelial carcinogenesis as humans advance in age. His telomeric instability model of epithelial carcinogenesis fits well with what is known about the timing of telomerase activation and evolving genomic changes during various stages of multistage process of carcinogenesis in humans, in particularly those of the breast and colon. The elucidation of causes of an agerelated increase in cancer incidence may be the key to a strategy for primary cancer prevention.

\section{Age-related increase in spontaneous tumor development}

It is well documented that the incidence of malignant tumors increases progressively with age, both in animals and humans $[1,2,8]$. The term 'spontaneous tumors' may be misleading, as the majority of these neoplasm are caused in humans by environmental factors, including tobacco smoking, diet, alcohol consumption, sexual promiscuity, industrial byproducts, ultraviolet radiations, drugs, and oncogenic viruses [22,23]. In experiments with rodents, it is commonly accepted that 'spontaneous tumors' mean neoplasia developed without any additional exposure to some exogenous carcinogen $[8,24]$.

The overall incidence of cancer increases with age, but this increment is not uniform for all types of cancer. In animals, genetic influences seem to control the occur- 
rence of age-related cancers, which are to a large extent species and strain specific [8,24]. For example, 80-90\% of AKR mice develop fatal leukemia between the ages of 7 and 10 months, whereas $90 \%$ of 18 -month-old strain A mice develop pulmonary adenomas. A similar incidence of spontaneous hepatoma is seen in 14-month-old male $\mathrm{C} 3 \mathrm{H}$ mice, whereas mammary adenocarcinoma affects $90 \%$ of 18-month-old females of the same strain. Endocrine tumors arise in $80-85 \%$ of older rats from some specific strains.

In humans, more than $80 \%$ of malignancies are diagnosed after age 50, In older humans, the influences of inheritable genetic abnormalities on carcinogenesis are unknown. A well known site-specific variation in the age-related incidence of cancer suggests a different susceptibility of different tissues to carcinogenesis. Dix et al. [25] subdivided all human tumors (except for chorionepithelioma) into two classes. The first class included all tumors whose incidence presents a single peak after age 50 . The majority of tumors belong to this class. The second class is composed of tumors having two peaks of incidence: the first before age 35 and the second after age 50. This class includes acute lymphocytic leukemia, osteosarcoma, and Hodgkin's disease.

The relationship of age with the incidence of benign tumors has not been satisfactorily studied, though benign neoplasia are more common than the malignant ones. Also, there is scarce data on the age-related distribution of tumors of different histogenesis found in the same organ. For example, epithelial carcinomas account for only a minority of ovarian cancers in women under 15 and germ cell neoplasms are most common in this group of women. The opposite is the case in women over 40 [8].

It is evident that the incidence of both total and fatal tumors decreases in the oldest groups of male and female mice [26]. The analysis of data on tumor incidence in ad libitum and calorie restricted mice $[27,28]$ shows the same. This result corresponds to observations on a decrease in cancer incidence in centenarians [29-32].

\section{Is the susceptibility to carcinogenesis similar in different tissues at different age?}

Animal experiments seem to confirm that there are age related differences in sensitivity to carcinogens in some tissues. Thus, with age, susceptibility to carcinogens in murine mammary gland, small intestine and colon, thyroid, ovarian follicular epithelium decreases; in subcutaneous tissue, cervix uteri, vagina increases and in others (lung, hemopoietic tissues) it remains stable (for details see: [7,8,13]). Sometime opposite directed age-related changes in the susceptibility to carcinogenesis have been observed in different tissues in one set of an experiment. For example, in female rats exposed to $N$-nitrosomethylurea (NMU) in doses 10,20 or $50 \mathrm{mg} /$ $\mathrm{kg}$ at the age of 3-month developed mammary carcinomas, tumors of the kidney, ovaries and colon. In contrast to young animals, the rats exposed to the same doses of the carcinogen at the age of 15 months showed a higher frequency of tumors of the corpus and cervix uteri following the exposure to NMU, and a lower frequency of mammary and intestinal adenocarcinomas and tumors of the ovary and kidney [33]. Comparison of the results with the data on DNA alkylation, DNA synthesis and $\mathrm{O}^{6}$-methylguanine repair obtained on the same model suggests a critical role of age-related proliferative activity changes occurring in the target tissues in the mechanism of age in modifying the effect on carcinogenesis. This conclusion is in agreement with an evidence that proliferation is necessary for both repair and mutation in cells [34]. Obviously, there are no common patterns of age related changes in DNA synthesis and repair or in proliferative activity of different tissues with age [8,13]. G35-A35 activating mutations in the Harvey ras gene were found only in mammary carcinomas from rats exposed to NMU at the age of 2 months, but not in tumors that developed on animals exposed to NMU at 15 months of age [35]. Thus, age at the time of carcinogen exposure plays a critical role in both mammary cancer susceptibility and the molecular events that contribute to mammary carcinoma development.

There are several possible reasons for this wide variation in experimental results. These include factors related to the experimental model and factors related to the tumor-host. Model-related factors involve the characteristics of different carcinogens (direct or indirect action, chemical structure, mechanism of action), route of administration, exposure duration, presence of local and systemic activity, and time of observation. Hostrelated factors involve animal species, strain, sex, and age. The effective dose of an indirect carcinogen, requiring metabolic activation, may vary significantly in old and young animals, because the activity of the enzymes necessary for carcinogen activation in the liver and/or target tissue(s) may change with age [36-38]. Critical factors that determine the susceptibility of a tissue to carcinogenesis include DNA synthesis and proliferative activity of that tissue at the time of carcinogen exposure, and the efficacy of repair of damaged DNA. The available data concerning age related changes of these parameters have been discussed elsewhere $[8,13,39,40]$.

The homeostatic regulation of cell numbers in normal tissues reflect a precise balance between cell proliferation and cell death. Programmed cell death (apoptosis) provides a protective mechanism from cancer, by removing DNA damaged, or diseased cells that could potentially interfere with normal function or lead to 
neoplastic transformation [40-42]. Apoptosis plays a substantial role in many other aspects of aging and cancer, including control of the life-span of most members of the immune complex, and the rate of tumor growth [43]. $p 53$ mediated apoptosis has been suggested as a safegard mechanism to prevent cell proliferation induced by oncogene activation [44].

Age related factors limiting the susceptibility to carcinogens are tissue specific $[8,13]$. This conclusion may explain, at least in part, both age related changes in susceptibility to carcinogenesis in target tissues, and organ and tissue variability in age distribution of spontaneous tumor incidence. This conclusion generates also a critical question: is aging accompanied by the accumulation in tissues of cell harboring premalignant lesisons?

\section{Aging and multi-stage carcinogenesis}

Both carcinogenesis and aging are associated with genomic alterations, which may act synergistically in causing cancer $[40,45-48]$. In particular, three recently described age-related changes in DNA metabolism may favor cell transformation and cancer growth. These changes are genetic instability, DNA hypomethylation, and formation of DNA adducts.

Genetic instability involves activation of genes that are normally suppressed, such as the cellular protooncogenes, and/or inactivation of some tumor suppression genes $(p 53, R b$, etc.) $[40,44]$. DNA hypomethylation is characteristic of aging, as well as of transformed cells. Hypomethylation, a potential mechanism of oncogene activation, may result in spontaneous deamination of cytosine and consequent base transition, i.e. substitution of the pair thymine:adenine. Accumulation of inappropriate base pairs may cause cell transformation by activation of cellular proto-oncogenes [40]. Age-related abnormalities of DNA metabolism may be, to some extent, tissue- and gene-specific. For example, hypomethylation of the c-myc proto-oncogene has been found in the hepatocytes, but not in the neurons of old mice $[49,50]$. Within the same cell, different DNA segments express different degrees of age-related hypomethylation. The uneven distribution of hypomethylation may underlie selective overexpression of protooncogenes by senescent cells. For example, the transcription of c-myc is progressively increased in the liver but not in the brain of rats between the ages of 4 and 22 months, whereas the transcription of c-sis and c-src does not appear to be age-related in any tissues $[49,50]$.

The different extent of DNA abnormalities among aging tissues may account in part for the different susceptibility of these tissues to carcinogens [45,51].

The damage caused by endogenous oxygen radicals has been proposed as a major contributor to both aging and cancer [52-54]. Endogenous oxidative damage to lipids and proteins increases with age [52,54]. It was shown that oxygen free radicals may induce active mutations of the human c-Ha-ras proto-oncogene [55]. The level of one oxidized nucleoside, 8-hydroxy-2'deoxyguanosine $(\mathrm{oh} 8 \mathrm{dG})$ in the DNA increased with age in liver, kidney, and intestine but remained unchanged within brain and testes of rats, whereas the urinary excretion of the nucleoside decreased with age of rats [56]. A variety of cellular defense systems are involved in protecting cellular macromolecules against devastating action of oxygen-based radicals. These systems include antioxidant enzymes $(\mathrm{Cu}, \mathrm{Zn}$ - superoxide dismutase (SOD), manganese-containing SOD, catalase, glutathione peroxidase, glutathione reductase, glucose-6-phosphate dehydrogenase), some vitamins ( $\alpha$ tocopherol, ascorbic acid), uric acid and the pineal indole hormone melatonin [57-60].

There is evidence of an age-related accumulation of spontaneous mutations in somatic and germ cells [47]. Accumulation with age of some spontaneous mutations or mutations evoked by endogenous mutagens can induce genome instability and, hence, increase the sensitivity to carcinogens and/or tumor promoters. It has been shown that clonally expanded mtDNA mutations accumulate with age in normal human tissues as well as in human tumors [61-63], The finding that deleted mtDNA accumulated in human muscle tissue as well as evidence for partially duplicated mtDNA in aged human tissues [64] allow to suggest the important role of clonal expansion of mutant mtDNA in the age-related increase of systemic oxidative stress in the whole organism [65]. A significant trend toward increasing p53 mutations frequency with advancing age was found in some normal and malignant tissues [66,67]. Simpson [12] suggests that the aging human body accumulates enough mutations to account for multistep catcinogenesis by selection of preexisting mutations. The evidence reported that both genetics of the selected cellular clone and the epigenetic of the selective environment contribute to tumor development [68].

In important aspect of the problem is an evaluation of the role of parental age in tumor development in the offspring. The progeny of 25 -month-old male rats mated with 3-month-old females was significantly susceptible to chemical carcinogen, NMU, in comparison to the progeny of young males [69]. Using the nationwide Swedish Family-Cancer Database to analyze the effect of parental age on cancer in offspring at ages 15-53 years, Hemminki and Kyyronen [70] have shown that paternal age increased rate ratios of sporadic nervous system cancers by about $15 \%$, whereas maternal age was associated with sporadic melanoma and leukemia, causing a $30 \%$ excess if it mothers were more 40 years versus less than 20 years of age. It was suggested that accumulation of chromosomal aberrations and muta- 
tions during the maturation of germ cells may be a mechanisms for these findings [70,71]. The odds ratio for retinoblastoma resulting from assumed new germ mutations among children of fathers aged 45 or more years was 3.0 [72]. In the same study it was shown that the risk of childhood acute lymphoblastic leukemia was significantly higher among children of older mothers and fathers, and significant trends with increasing mothers's and fathers' ages were found. It is worthy nothing that spermatogenic cells from old mice have significantly increased mutation frequencies compared with spermatogenic cells from young or middle-aged mice [73]. New dominant mutation rise exponentially with parental age but not matergnal age in humans [74].

Thus, the data available show that some changes in structure and function of DNA are evolving with natural aging. The character of these changes could vary in different tissues and might cause uneven tissue aging. Recently, Dolle et al. [75] using a lacZ plasmid transgenic mouse model, determined spectra of spontaneous point mutations in different organs in young and old mice. While similar at a young age, the mutation spectra among these organs were significantly different in old age. The authors stressed that the replicative history per se is not the underlying causal factor of agerelated organ-specific differences in mutations spectra. Rather, differences in organ function, possibly with association with replicative history, may explain the divergence in mutation spectra during aging. In turn, this may explain both age-related increase in spontaneous tumor incidence and age-related changes in susceptibility to carcinogens in various organs.

Carcinogenesis is a multistage process: neoplastic transformation implies the engagement of a cell through sequential stages, and different agents may affect the transition between continuous stages [76-81]. Multistage carcinogenesis is accompanied by disturbances in tissue homeostasis and perturbations in nervous, hormonal, and metabolic factors which may affect antitumor resistance. The development of these changes depends on the susceptibility of various systems to a carcinogen and on the dose of the carcinogen. Changes in the microenvironment may condition key carcinogenic events and determine the duration of each carcinogenic stage, and sometimes they may even reverse the process of carcinogenesis. These microenvironmental changes influence the proliferation rate of transformed cells together, the total duration of carcinogenesis and, consequently, the latent period of tumor development (Fig. 1).

Cross-talk between mesenchyme and epithelium has been described as a known driver of differentiation and development $[82,83]$. It was shown that changes in stromal behavior can promote epithelial transformation [20,82,84].
There are also evidence of age-related accumulation of cells which are in the late stage of multi-stage process of carcinogenesis. Numerous experiments support this model. Thus, single skin application with 7,12-dimethylbenz[a]anthracene (DMBA) in mice aged 8 and 48 weeks at doses ranging from 10 to $300 \mu \mathrm{g}$ caused increased skin papilloma incidence in older mice (Table 1) [85]. Also, the average diameter of the tumors was larger in the older animals. Likewise, the incidence of skin papillomas after 12- $O$-tetradecanoylphorbol-13-acetate (TPA) application was 6 -fold higher in 14-month-old mice than in 4-month-old.

Of particular interest are the experiments using skin transplants. TPA failed to induce tumors in the skin of 2-month-old mice grafted to animals of different ages, but caused the same tumor incidence in the skin of 1year-old donors irrespective of the recipient's age [86]. These results indicate that the age of the target tissue, more than the age of the host, determines susceptibility to late-stage agents. Delaying wounding 16 weeks after initiation with a carcinogen led to a more pronounced skin tumor response compared with delay of only 6 weeks in young mice [87]. Delaying promotion has also been reported to lead to an increased tumor response with the promoter chrysarobin [88] or mezerein [89]. These findings are in agreement with data on age-related decrease in cellular DNA repair capacity in skin [90,91] and increasing $p 53$ mutation frequency with advancing age in human normal skin [66] and in basal-cell skin carcinomas [67,92]. There was observed age-related decline in post-ultraviolet DNA repair capacity and corresponding age-related increase in post-ultraviolet mutability in cultured primary skin fibroblasts from normal donors from the first to the tenth decade of life [90]. It was suggested that there was the age-related increase in the number of telomerase positive basal cells in the skin [93]. However, in some studies the papilloma response either decreased with age or was the same as the response in younger mice [94-96].

In Tg.AC transgenic (v-Ha-ras) mice, skin tumor incidence and multiplicity were strongly age-dependent, increasing with increasing age of the animal when first treated with TPA or exposed to wounding or UV-light (Table 2) [97]. The authors suggest that natural developmental changes in keratinocytes are co-opted by the molecular mechanisms that regulate the induction of transgene expression, thus stimulating tumor formation in older Tg.AC mice.

Age-related accumulation of cells in advanced carcinogenic stages may also be inferred by other types of experiments. The mouse model of hepatocarcinogenesis is very convenient for this purpose because of the availability of strains of animals with different susceptibility to hepatic carcinogenesis. In the liver of highly susceptible mice, the concentration of hepatocytes in advanced stages of carcinogenesis was increased early in 


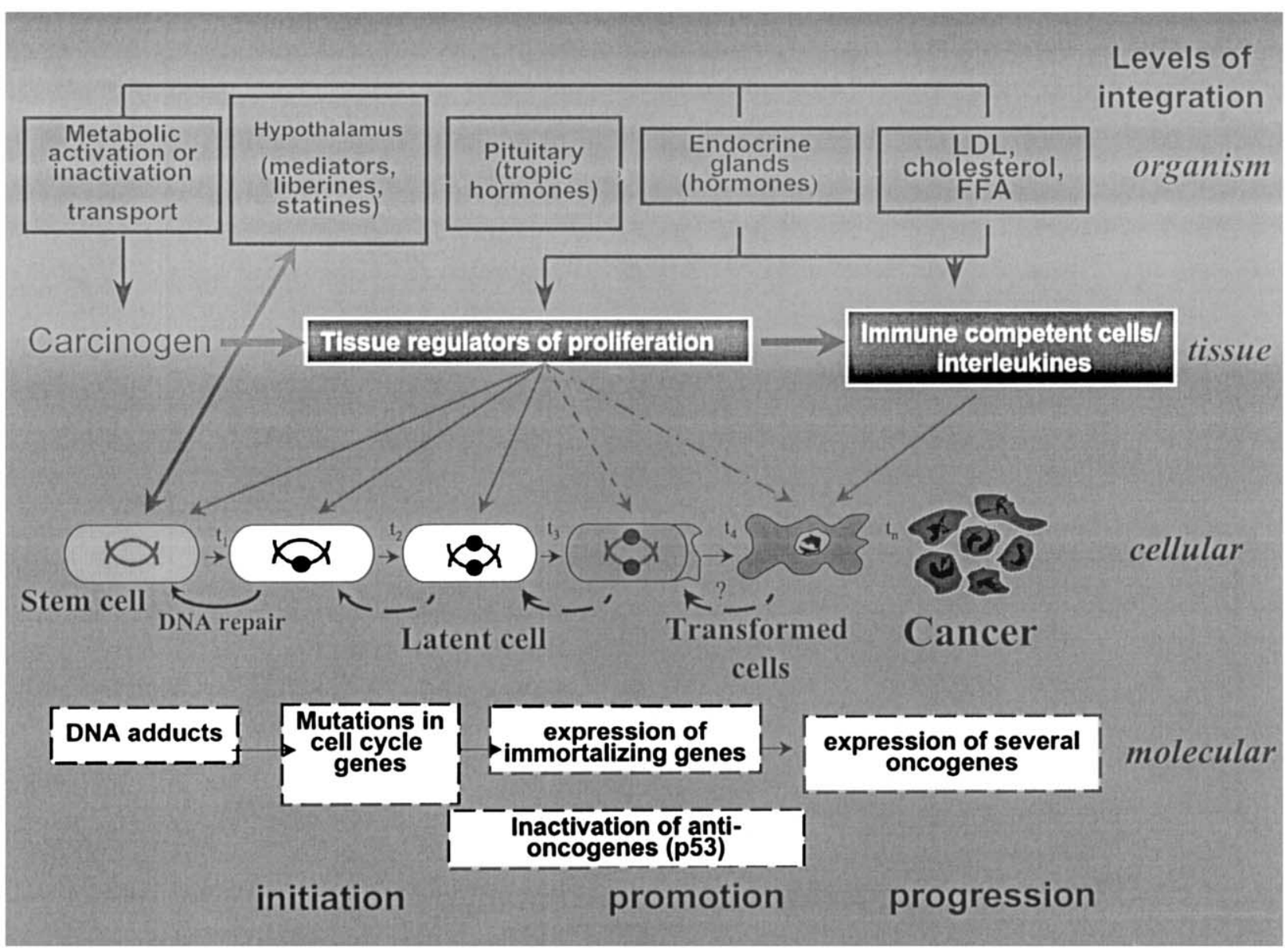

Fig. 1. The integral scheme of carcinogenesis [13]. During the first stage of carcinogenesis (initiation) irreversible changes in the genotype of the normal target stem cell leading to its immortality take place.During the initiation the carcinogen or its active metabolite(s) (derived by simple degradation or by active enzymatic process) interacts with nucleic acids leading to mutations in oncogenes and in anti-oncogenes.During the second stage of carcinogenesis (promotion) an initiated (latent, immortalized) cell acquires phenotypic features of transformed (malignant) cell, and under the factors of microenvironment can undergo to tumor progression. A carcinogen affects not only target cell but also influence a lot of factors in the microenvironment of the target cell creating a conditions for promotion of immortalized cell (growth factors, cytokines, immunodepression, biogenic amines, hormonal and metabolic imbalance). A complete carcinogens affect both stages of carcinogenesis (initiation and promotion) whereas tumor promoters affect only the second stage.

Table 1

Age-dependence of skin carcinogenesis induced by a single DMBA application (adapted from Stenback et al. [85])

\begin{tabular}{lll}
\hline Dose of DMBA $(\mu \mathrm{g})$ & \multicolumn{2}{l}{ Age (incidence of skin tumors $(\%))$} \\
\cline { 2 - 3 } & 8 weeks & 48 weeks \\
\hline 10 & 0 & 1.3 \\
30 & 0 & 6.3 \\
100 & 21 & 18 \\
300 & 30 & 47 \\
\hline
\end{tabular}

life before the exposure to experimental carcinogens [98]. In the liver of F344 rats the number of spontaneous proliferative foci is proportional to the animal age [99101]. The incidence of proliferative foci and hepatic tumors induced by phenobarbital, carbon tetrachloride or peroxisome proliferators in rodents is also a function of age [100-102].
Table 2

Age-dependence of skin tumorigenesis in Tg.AC (v-Ha-ras) transgenic mice exposed to TPA, skin wounding or ultra-violet radiation (adapted from Battalora et al. [97])

\begin{tabular}{lll}
\hline \multirow{2}{*}{ Treatment } & \multicolumn{2}{l}{$\begin{array}{l}\text { Age at start of treatment (mean number of } \\
\text { papillomas per mouse) }\end{array}$} \\
\cline { 2 - 3 } & 10 weeks & 32 weeks \\
\hline $4 \times 2.5 \mu \mathrm{g}$ TPA & 0.7 & 12.0 \\
$4 \times 5.0 \mu \mathrm{g}$ TPA & 5.9 & 27.8 \\
$4 \times 10.0 \mu \mathrm{g}$ TPA & 16.9 & 23.5 \\
Wounding & 0.9 & 5.4 \\
UV radiation & 2.4 & 8.3 \\
\hline
\end{tabular}

Another pertinent model involves induction of lymphomas in mice receiving transplants of splenic, thymic and lymphoid cells from syngeneic donors [103]. The incidence of neoplasms developed was related to the age 
Table 3

Age-dependence of tumorigenesis induced by exposure to tumor promoters alone

\begin{tabular}{lllcrr}
\hline Target tissue & Species & Agent & Age groups (months) & Effect & References \\
\hline Skin & Mouse & TPA & 4,14 & Increases & {$[86]$} \\
Liver & Mouse & Phenobarbital & $1.5,12$ & Increases & {$[100]$} \\
& Rat & Phenobarbital & 1,26 & Increases & {$[102]$} \\
& & Partial hepatectomy+phenobarbital & 5,18 & Increases & {$[106]$} \\
& & Carbone tetrachloride & $1-6,12$ & Increases & {$[107]$} \\
Mammary gland & & Clofibrate, nafenopin & 3,18 & Increases \\
Ovary & Rat & Estradiol & 1,20 & Increases & {$[104,105]$} \\
\hline
\end{tabular}

a Transplantation of the ovary into the spleen after ovariectomy.

of the donor, but not to the age of the recipient. Geschickter [104,105] observed mammary tumor development in estrogen-treated 1- and 20-month-old rats with a latency period of 9.5 and 3.0 months, respectively. The data on age-related susceptibility to tumor promoters are given in Table 3.

Single intravenous injection of NMU at doses of 10 , 20 or $50 \mathrm{mg} / \mathrm{kg}$ was administered to female rats aged 3 or 15 months [33]. The NMU carcinogenic dose dependence in different age groups was considered in the context of a multi-stage model. It was calculated that the number of events necessary for complete malignant transformation in 15-month-old rats under the influence of NMU was lower than in 3-month-old. In this experiment as well as in another sets of experiments in rats and in mice it was shown that tumors developed earlier in older than in younger animals after exposure to the same doses of NMU [109-111]. The combined incidences of severe endometrial hyperplasia and adenocarcinomas tended to increase with the increase in intervals between a start of promoting estrasiol treatment after $N$-nitrosoethylurea initiation in mice [112]. A new optical-probe technique based on light-scattering spectroscopy has the high potential to detect epithelial precancerous lesions and preinvasive cancers throughout the body [113] and may be fruitful for quantitative evaluation of its age-related accumulation in various tissues.

Some in vitro observations also support this point of view. Thus, transformed by $24 \mathrm{~h}$ exposure to DMBA, foci in murine bladder epithelium have appeared earlier (on the 40th to the 60th day) and more often (25\%) in explants of old (28-30 months) donors in comparison with 100 days and $0.9 \%$ in cultures received from 5 to 7 month-old mice. A spontaneous transformation of bladder epithelium occurred only in the explants received from old donors [114]. The aging of the tissue donor was associated with increased susceptibility of primary cultures of rat fibroblasts to transformation induced by SV-40 [115]. Contrary, Nettesheim et al. [116] reported that the sensitivity of trachea epithelium explants of old animals was lower in comparison to explants from young animals.

An important question related to the integrated carcinogenic model concerns age-related changes in tissue microenvironment as these changes may both favor or oppose carcinogenesis in different circumstances. Should aging tissues alter the environment in which tumor develops, the growth rate of transplantable tumors may vary with the age of the tumor recipient [3]. These experiments bypass the effect of age on carcinogenesis itself and explore the role of age-related changes in the organism on the growth and progression of transformed cells. Evaluation criteria for such experiments should include; (1) tumor transplantability, (2) rate of tumor growth, and (3) survival time of tumor bearing animals. The natural history of spontaneous tumors in humans (the rate of tumor doubling, metastasizing potential) and on the survival of cancer patients newly diagnosed at different ages provide information on the effects of age on tumor growth in humans. Available data both in experimental animals and in humans are contradictory and support different effects of age on tumor development [8,117-119]. Tissue origin (histogenesis) and immunogenicity of tumor are the principal factors determining age-related differences in tumor growth. In general, an 'age effect' may be recognized both in experimental and in human malignancies.

There is increasing evidence that age-related changes in tumor microenvironment might play also a significant role. In our experiments, cells of rat rhabdomyosarcoma RA-2 selected for affinity to lung tissue were intravenously inoculated into rats of different ages [120]. It was observed that the number of lung tumor colonies was highest in 1- and 15-month-old animals and lowest in 3and 12-month-old animals. A positive correlation was found between the number of tumor lung colonies and somatomedine (IGF-I) activity in the lung. In another experiment, RA-2 cells from a 3-month-old donor were inoculated into 2-3- or 21-23-month-old recipients and 3 weeks later were separately taken from young and old hosts and transplanted into 3-month-old recipients. The 


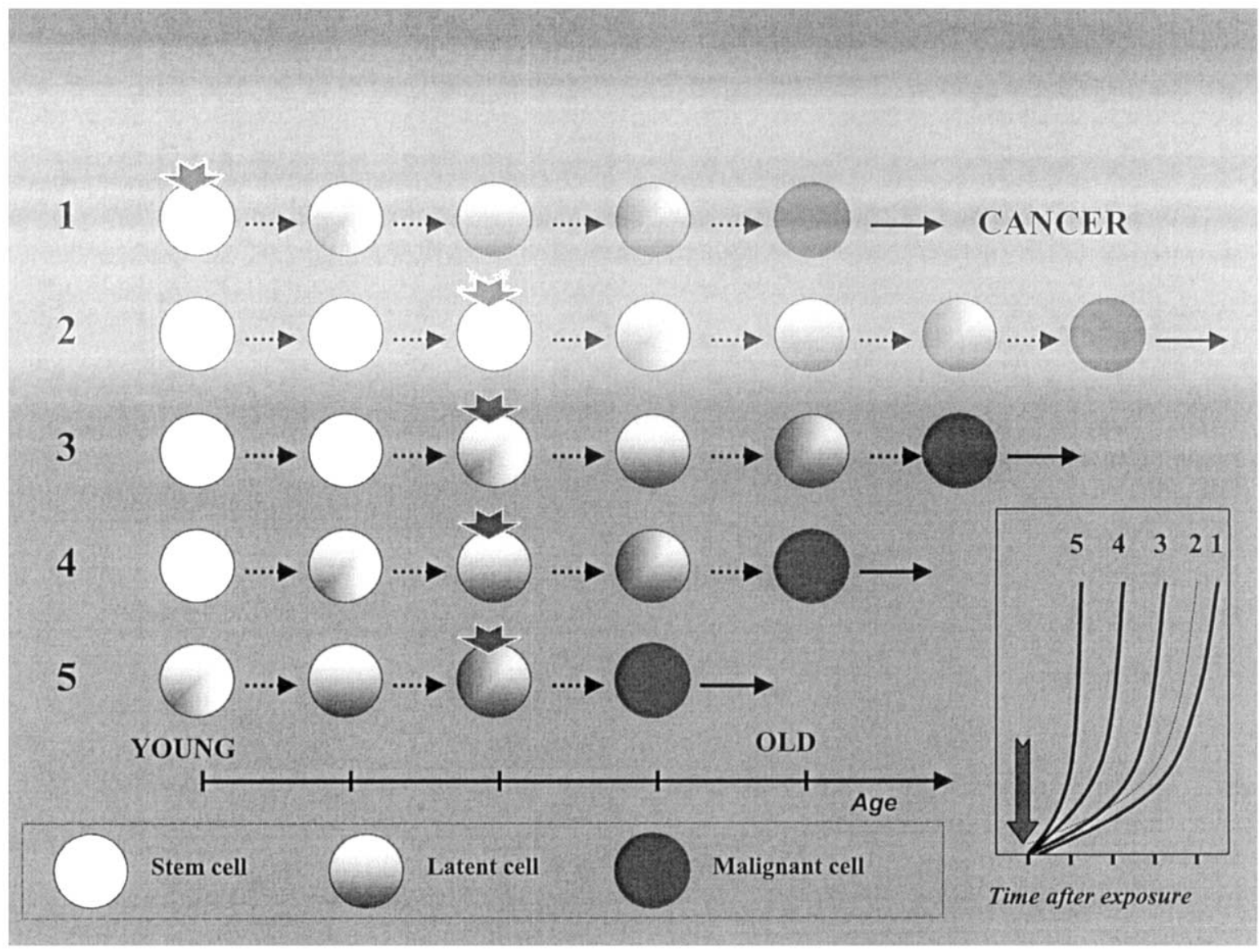

Fig. 2. Multistage carcinogenesis at differnet age [13]. An exposure to a carcinogen at young and older age can affect intact stem cell to drive it to multistep process of carcinogenesis (four to six stages) (lines 1 and 2). In his case, if enzyme activity, DNA repair and proliferative activity of target tissue is equal, the incidence and the latency of tumor can be similar in both age group. In some case an exposure to a carcinogen at older age affects cell which passed one and more stages and acquired some features of precancer (immortalily) under influence of genetic predisposition (inherent mutations in oncogenes or anti-oncogenes) or endogenous carcinogenic factors, oxidative stress including (lines $3-5$ ). In this case much less stages will be nesessary for transition to complete transformation (only one in the case of melanoma).

number of lung colonies was significantly decreased in 3month-old recipients injected with RA-2 cell passed via old host [121]. The results obtained suggest the critical role of host and donor microenvironment in lung colony forming potential of RA-2 cells.

McCullough et al. [122] have observed that transformed rat hepatocytic cells lines were only weakly tumorigenic following transplantation into the livers of young adult rats. The tumorigenicity of these cell lines increased progressively with the age of the tumor recipients. These results suggest strongly that the tissue microenvironment represents an important determinant in the age-related tumorigenic potential of transformed cells.

It is important to stress that in every tissue the number of events occurring in the stem cell before its complete transformation is variable and depends on many factors, in particular the rate of aging of the target tissue and its regulatory system(s) $[13,33,111]$. This model is consistent with the analysis of age-related distribution of tumor incidence in different sites in humans and laboratory animals [2,8]. It must be emphasized also that old animals can be used as an adequate model for long-term assay for carcinogenicity of suggested weak carcinogens and/or tumor promoters. (Fig. 2).

\section{Cellular senescence and carcinogenesis}

In contrast to germ cells and certain stem cells, the majority of somatic cell types have a limited proliferative life span in vitro. After a finite number of cell division (50-70 for human embryonal fibroblasts) normal human somatic cells enter a nonreplicative stage called cellular senescence, also designated as mortality stage 1 or M1 $[123,124]$. A $\beta$-galactosidase acivity has been shown to be activated in senescent cells and it is generally not detected in either quiescent or terminally differentiated cells $[125,126]$. It is well documented that 
transfection with either SV40 large $\mathrm{T}$ antigen protein, the adenovirus E1 A and E1B proteins, or HPV E6/E7 proteins causes a significant extension of in vitro life span caused by the interference of the viral proteins with the $p 53$ and $R b$ pathways [127]. At the end of the extended life span phase another proliferative decline is observed which has been designated as a crisis or mortality stage 2 (M2) and a small, but significant fraction of cells in M2 can become immortalized [124]. It has been proposed that while the proliferative decline at senescence is primarily due to a decline in cell division, the proliferative decline at crisis is caused by an increase in cell death that is balanced by continuing cell division [128]. It worthy to note that there is a negative correlation between donor age and proliferative life span in vitro [123]. Cell cultures, established from donos with various diseases, including diabetes mellitus, Werner syndrome, Hutchinson-Gilford syndrome and Down's syndrome also exhibit decreased proliferative potential [123]. However, it was shown, that if health status and biopsy conditions are well controlled, the replicative senescence of human fibroblasts in culture does not correlate with donor age [129].

The replicative senescence may have evolved as a protective mechanism against cancer, although it may also cause accumulation of cells at the end of their replicative life span that may be responsible for aging process and increased the susceptibility to carcinogenesis $[17-19,123]$. It is worthy to note that successful chemotherapy of murine tumors engaged a senescence program controlled by $p 53$ and $p 16^{I N K 4 a}$ whereas mice harboring tumors with senescence defects have much worse prognosis [130].

Somatic cells from some species (e.g. fishes) have an immortal phenotype but these organisms do not develop more cancers than other species [131]. Susceptibility to transformation varies during the different stages of proliferate senescence depending on the carcinogen. Thus, young cells are more susceptible to transformation by chemical carcinogens and by low-dose ionizing radiation, susceptibility to ultraviolet radiation is identical throughout the life span of human fibroblasts, whereas susceptibility to a tumor promoter is identical through the cell life span with exception of the final stage, and susceptibility to SV40 is highest during the final stage [131,132]. Rat embryonal fibroblasts were much susceptible to $\mathrm{v}-\mathrm{scr}$ transformation than when they were isolated from an adult rat [133]. Studying the role of organismic development and aging in oncogene transformation of primary cells it was shown that aging of the tissue donor was associated with increased susceptibility of primary culture to SV-LT transformation [115].

The oncogene ras provokes premature senescence in primary rodent and human cells in association with the induction of $p 53$ and $p 16$ [134]. Authors proposed that premature induction of cellular senescence in response to abnormal mitogenic signaling is a mechanism of tumor suppression. Inactivation of this antiproliferative response allows proliferation to continue unabated in the presence of oncogenic stimuli. These observations could explain the apparent pressure to mutate genes involved in the establishment of oncogen-induced senescence, such as $p 53$ and $p 16$, during tumor progression [134]. The induction of cellular senescence in response to a potent oncogene such as ras indicates that senescence is a programmed cellular response that can be triggered not only by the accumulation of cell doubling, but also by some proliferative stresses [135]. Using microarray analysis for assessing senescence-associated gene expression in dermal fibroblasts, retinal pigment epithelial cells, and vascular endothelial cells, it has been shown that the characteristics of the senescence response were highly cell-specific [136]. Fibroblasts demonstrated a strong inflammatory-type response, but shared limited overlap in senescence gene expression patterns with the other two cell lines.

In recent years, the importance of telomeres in aging has been highlighted. Telomeres are DNA sequences found at the end of eukaryotic chromosomes in somatic cells. During cell replication, telomeres are preserved by the enzyme telomerase, a ribonucleoprotein enzyme that adds the telomere sequences TTAGGG to chromosome ends $[19,137,138]$. In the absence of telomerase, telomere is shortened with each cell division. Loss of the distal region of telomeres correlates with the decline of the proliferative life-span of cells both in vitro and in vivo $[138,139]$. Using regression analysis of data on rates of telomere length reduction in 15 human cells, tissues and organs, Takubo et al. [140] have shown their values within the range of 20-60 bp/year. The authors stressed that telomere lengths did not show clear correlation with tissue renewal times in vivo, but rather were characteristic for individuals.

There are serious arguments supporting a hypothesis that telomere shortening and reactivation of telomerase are important components of aging and carcinogenesis, respectively $[19,141]$. It was suggested that a major function of wild-type $p 53$ may be to signal growth arrest in response to telomere loss in senescent cells [142]. This hypothesis is consistent with the behavior of most tumors that exhibit p53 mutation and also explain the existence and characteristics of rarer tumor types in which $p 53$ function appears to be retained.

Krtolica et al. [20] have shown that senescent human fibroblasts stimulate premalignant and malignant, but not normal, epithelial cells to proliferate in culture and form tumors in nude mice. It is important that the effect of presenescent fibroblasts was less than of senescent ones. It was also observed that young (early passage, having lived less than $30 \%$ of their proliferative life spans) human endometrial stromal cells from adults 
inhibited the malignancy-associated trait of anchorageindependent proliferation of the endometrial epithelial cancer cells, whereas the stromal cells aged in vitro (had lived $90 \%$ of their replicative life spans), they lost this capacity [21].

It is worthy to note that senescence is not an inevitable consequence of extended proliferation in culture. Thus, rat Schwann cells appear to have the capacity for unlimited proliferation in vitro, whereas fibroblasts isolated from the same nerves undergo the classic replicative senescence seen in rodent fibroblasts [143]. It was found that human endothelial cells from the umbilical vein arrest in the G1-phase of the cell cycle but, unlike fibroblasts, undegro age-dependent tetraploidization and undergo apoptotic cell death, in strong contrast to the apoptotic-resistant fibroblasts [144]. Some other normal rodent precursor cells (e.g. oligodendrocytes) have an unlimited proliferative capacity if cultured in conditions that avoid both differentiation and the activation of check-point resposes that arrest the cell cycle [145]. In contrast to fibroblasts, human mammary epithelial cells spontaneousy escape senescence and generate genomic abnormalities that are required for the initiation of carcinogenesis [146]. In this study over the course of 75 population doublings, the proliferation, survival, karyotype, telomeric length and levels of $p 53, p 21$ and $p 14$ were recorded. Cells surviving the selection process appear to have lost $p 16$ expression, an event that correlates with their release from growth arrest. Then, during the second phase of exponential growth, cells begin to accrue chromosomal abnormalities. Consistent with these findings is the observation that the mammary epithelial cells undergo progressive telomeric shortening. At the same time, levels of proteins $p 53$ and its modulator $(p 14)$ and effector (p21) were rised, suggesting that in vitro agonescent mammary cells (termed so to distinguish it from the single growth plateau of senescence observed in fibroblasts) effectively evade $p 53$ regulation. These studies suggest that aging mammary epithelia are capable of spontaneously generating genomic abnormalities that are required for the genesis of a cancer cell [147]. Although telomerase activity is elevated in ductal breast carcinomas and their immediate precursors, there is no evidence yet for telomeric shortening between normal and malignant mammary tissues [148]. It seems that cellular senescence may not take place in some epithelial cells. It is worthy to note that the evidence supporting the relevance of replicative senescence of human cells and telomere biology to human cancer is now quite strong, however, the evidence linking relicative senescence to human aging is controversial and required additional studies $[149,150]$.

Gap junction-mediated communication decrease is one of important features of neoplastic cell $[40,48]$. This parameter has been decreased also in senescent human endothelial cells [151]. The levels of connexin 42 messenger RNA and protein decline were revealed as these cells age in vitro. The inability of senescent cells to down-regulate gap junctions in response to epidermal growth factor reflect a defect in the regulatory mechanism of gap junction activity in senescent cells [151].

It is necessary to stress that in vivo stem cells have no any replicative limit. Thus, calculations based on the knowledge of the cell cycle length have shown that germinal cell of the mouse tongue undergoes about 565 doublings during a 2 years life span [152]. Stem cells of the mouse small intestine undergo between 820 and 2200 doublings in a lifetime without evidence of cell death [153]. Reviewing the data on cell aging in vitro and in vivo, Rubin [154] concluded that there is no reason to believe that the Hayflick limit occurs in self-renewing tissues in vivo or contribute to aging of the organism. One of the real feature of aging in vivo is reduction of cell proliferation observed in the majority of tissues of rodents $[8,154-156]$. The increase in cell cycle time and its variance have been mainly observed. The relationship between aging and carcinogenesis both in vitro and in vivo is schematically presented at Fig. 3.

\section{Do carcinogens accelerate aging?}

Given the similarity of molecular changes of aging and carcinogenesis it is reasonable to ask whether and how carcinogens may affect aging. The ability of carcinogens to influence aging has been discussed for many years. Larionov [157] reported that the exposure of rodents to polycyclic hydrocarbons was followed by features of premature aging. Neonatal exposure to DMBA decreased the life-span of mice and has been accompanied by premature cessation of estrus function, hair discoloration, and loss of body weight [158]. In our own experiments, female rats treated with 20 -methylcholanthrene manifested a number of endocrine and hormone-metabolic changes typical of aging animals, including a cessation of estrus cycle [159]. Chronic inhalation of tobacco smoke caused enhanced production of free radicals and signs of aging in rats [160]. Acceleration of aging by ionizing radiation has been well documented and epitomizes dose-dependent effects of carcinogens on aging [161-164]. Exposure to extremely low-frequency electromagnetic fields $(50 / 60 \mathrm{~Hz})$ which has weak tumor-promoting effects in some experimental systems [165-167], was followed by an acceleration of aging of endocrine and immune systems [168].

The effects of carcinogens on the neural, endocrine and immune systems, and on carbohydrate and lipid metabolism leading to an acceleration of aging are summarized elsewhere $[8,11]$. Ionizing radiation and chemical carcinogens appear to cause disturbances in the internal tissue milieu, similar to those of normal 


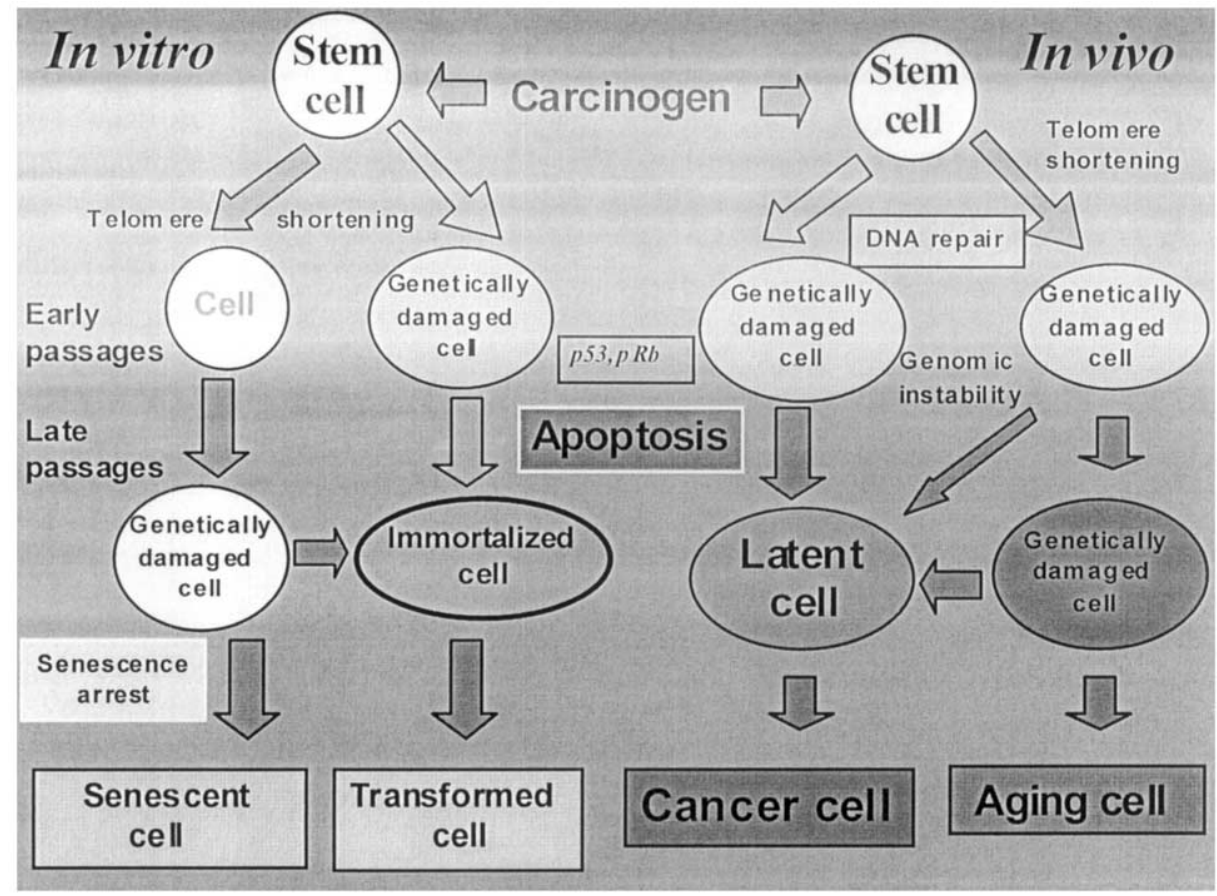

Fig. 3. Aging and carcinogenesis in vitro and in vivo. Normal human fibroblasts undergo a limited number of divisions in vitro enter a nonreplicative stage called cellular senescence. During aging in vivo normal cells accumulate damage over a lifetime that results in gradual loss of differentiated function and growth rate accompanied by an increased probability for development of cancer. Somatic stem cells in vivo have no any proliferative limit but the rate of proliferation activity in the majority of tissues decreases with the aging. Stem cells at the last passages in vitro and in vivo with age have reduced telomere length and accumulate damages leading to genome instability. Being exposed to a carcinogen, during several transition normal cell became initiated (immortal) and via several transitions-transformed (malignant). An exposure to a carcinogen leads acceleration of cellular senescence in vitro and to aging of an organism in vivo.

aging, but at an earlier age. Carcinogenic factors (including irradiation) cause a sharp transition to an 'older' level of function in metabolic processes, hormonal and immune status [8,162]. This transition is asynchronous and has different latent periods in various structures and systems of the exposed organism.

The intensity of natural damages to DNA is very high, e.g. in a human cell, spontaneous depurinization takes place at a rate of up to 10000 acts per day and spontaneous deamination of adenine and cytosine at a rate of hundreds events per day [169]. As a result, permanently working mechanisms of DNA repair have evolved. It turns out that in both of the most intensive natural mutation processes (depurinization and deamination), thymine is not present (mutations related to it are significantly more rare [169], and therefore, the reparation schemes for thymine may have evolved less intensively. Hence, if we want to induce uniformly distributed point mutations (and simultaneously to minimize damages in other structures) in laboratory animals then it is meaningful to use analogues of thymine as a mutagen.

Some in vitro and in vivo effects of the thymidine analogue, 5-bromodeoxyuridine (BrdUrd), suggest that BrdUrd may be used to investigate the role of selective DNA damage both in carcinogenesis and in aging.
BrdUrd is incorporated into replicating DNA in place of thymidine, and this effect is mutagenic [170]. In addition to the usual keto form, BrdUrd may assume an enol tautomeric form, which forms hydrogen bonds with guanine instead of adenine, the normal pair for thymidine and 5-bromouracil. In the absence of 5-bromouracil repair in rat DNA [171], if BrdUrd is incorporated into DNA as the enol tautomer, base pair substitution mutations are expected to occur $(\mathrm{GC} \rightarrow \mathrm{AT}$ and $\mathrm{AT} \rightarrow$ GC transitions) during subsequent DNA replication [170]. Unlike purine-analogues, BrdUrd is not involved in energy production or in cell-signaling and interactions and hence can reach required levels of mutations, while being less toxic than in the case of 'spoiled' analogues of purines [172]. This ability to induce uniformly distributed point mutations with a chosen intensity using BrdUrd is based on the fact that the number of mutations is linearly dependent on the concentration of BrdUrd [170,173,174]. Craddock [175] observed a dose-dependent shortening in life-span of rats exposed to BrdUrd in early life, in uncontrolled experiments, without data on tumor incidence or on biomarkers of aging.

Assuming a fairly even level of BrdUrd incorporation into the DNA of various tissues of neonatal rats and long-term persistence in them [176], cells with highest 
proliferative activity would be more likely to undergo malignant transformation. Exposure to BrdUrd had dramatic effects on cellular functions including cell differentiation, inactivation of regulatory genes or master switch [177], and proliferation [178]. These changes in cellular function may favor tumor development.

In a series of our experiments $[173,176,179]$ rats received subcutaneous injections of BrdUrd at 1, 3,7 and 21 days of postnatal life at the single dose of $3.2 \mathrm{mg}$ per rat. BrdUrd persi sted for up to 49 weeks in all tissues studied immunohistochemically, especially in tissues with normal or low cell turnover. For cells with high turnover few or no BrdUrd labeled cells remained at 49 weeks [176] exposure to BrdUrd was followed by the decrease in the mean life-span of the animals of $38 \%$ in males and $27 \%$ in females and by the increase in the rate of aging (calculated according to Gompertz equation) in comparison to controls. The monitoring of estrus showed an acceleration of natural age-related switching-off of reproductive function in female rats, due to disturbances in central regulation of gonadotropic function in the pituitary. The exposure of rats to BrdUrd was followed by signs of immunodepression, by increase in the incidence of chromosome aberrations and spontaneous tumors. The latency of these tumors was decreased. In offspring of rats neonatally treated with BrdUrd the increased incidence of congenital malformation and of spontaneous tumors, and accelerated aging were both observed. Neonatal exposure of rats or mice to BrdUrd was followed by the initiation of the neoplastic process and, consequently, by increased tissue susceptibility to 'late stage' carcinogens such as NMU; X-irradiation; urethane; estradiol-benzoate; persistent estrus syndrome and TPA $[173,179,180]$.

We also evaluated the effect of DNA damages induced by neonatal exposure to BrdUrd on susceptibility of target tissues to carcinogenic effect of NMU injected at various ages [110]. Rats exposed to BrdUrd in the neonatal period received single injections of NMU at doses of 10 or $50 \mathrm{mg} / \mathrm{kg}$ at the age of 3 or 15 months. In the absence of BrdUrd pretreatment, the carcinogenic effect of NMU was dose-dependent in the 3-month old rats, but not in the 15-month old. The susceptibility to NMU-induced tumors was decreased, but the tumorrelated survival was also decreased in the older animals. These data suggest age-related decrement in the effect of NMU and, at the same time, age-related decrease in the number of events which are necessary for tumor development. The exposure to BrdUrd was followed by increased susceptibility to the carcinogenic effect of NMU both in 3 and 15-month-old rats. These effects were largely confined to NMU-target tissues. The incidence of tumors in rats exposed to BrdUrd plus NMU at the dose of $10 \mathrm{mg} / \mathrm{kg}$ was equal to that in the rats to whom the carcinogen was injected at the age of 3 or 15 months, however, the survival of fatal tumorbearing rats was significantly decreased for the older animals. When NMU was injected at the dose of $50 \mathrm{mg} /$ $\mathrm{kg}$ in BrdUrd-pretreated rats, both the relative risk of tumors and the tumor-specific survival were decreased in the older animals [110]. Thus, our data have shown the long-term persistence of initiating effect of neonatal treatment with BrdUrd and provided the evidence that a sole perturbation of DNA induced by BrdUrd contributed substantially to the initiation of tumorigenesis and to the acceleration of aging.

BrdUrd was found to induce in vitro flat and enlarged cell shape, characteristics of senescent cells, and senescence-associated beta-galactosidase in mammalian cells regardless of cell type or species. In immortal human cells, fibronectin, collagenase I, and $p 21$ (wafl/sdi-1) mRNAs were immediately and very strongly induced, and the mortality marker mortalin changed to the mortal type from the immortal type. Human cell lines lacking functional $p 21$ (wafl/sdi-1), p16 (ink4a), or $p 53$ behaved similarly. The protein levels of p16(ink4a) and p53 did not change uniformly, while the level of p21 (wafl/sdi-l) was increased by varying degrees in positive cell lines. Telomerase activity was suppressed in positive cell lines, but accelerated telomere shortening was not observed in tumor cell lines [181,182]. These results suggest that BrdUrd induced senescence-like phenotypic resemblance in both mortal and immortal mammalian cells and, possibly, activated a common senescence pathway present in both types of cells [182]. The level of gene expression in HeLa cells and normal human diploid fibroblasts, TIG7 cells, exposed to BrdUrd has been examined [182]. BrdUrd induced expression of various known and novel genes in addition to several senescence-marker genes in HeLa cells, and more than half of these genes were found to be induced in normally senescent human fibroblasts. The affected genes in BrdUrd-treaded HeLa cells include those involved in remodeling of extracellular matrix, cell cycle progression, and metabolism of intracellular compounds essential for normal cell growth. The authors believe that this observation can explain features characteristic of normally senesced cells, e.g. specific morphological changes and the cell cycle arrest at the G1/S boundary, and supports their view that BrdUrd induces a senescence-like phenomenon. In new set of in vitro experiment, it was shown that BrdUrd clearly activates a silenced transgene integrated in HeLa cells [183]. The authors suggest that similar mechanisms may operate in the regulation of the BrdUrd-inducible genes and the senescence-associated genes. It is important to stress that BrdUrd immediately induces premature senescence in normal cells and the senescence-like phenomenon in any type of immortal cells [184]. Using cDNA microarray technique, the authors examined expression levels of approximately $800 \mathrm{cDNA}$ clones 
from HeLa cells and normal human fibroblasts cultured under various conditions. It was found that 478 clones were up-regulated in BrdUrd-treated HeLa cells, and more than half of them were induced in senescent human fibroblasts.

The mathematical model of processes of aging and carcinogensesis in tissue based on the experimental data on in vivo exposure to BrdUrd [110,173,179,180] has been considered [172]. Modeling was carried out on the basis of the recurrent algorithms constructed on the stochastic equations in terms of semimartingale characteristics of the processes. The results confirm the conclusion that under BrdUrd treatment there is an accelerated aging in tissues with proliferating cells and an increment of death from tumor growth. These results can serve as an indirect validation of the hypothesis about the influence of levels of tissue damages during mutagenesis and oxidative stress both on the rates of aging and on the rate of carcinogenesis. The above mentioned observation on in vitro effects of BrdUrd [181-184] is in agreement with this conclusion.

\section{Do premature aging promote carcinogenesis?}

It is well known that some syndromes of untimely aging (e.g. progeria) are associated with an increased incidence of cancer [185-187]. Three syndromes, Bloom's syndrome, Werner's syndrome and Rothmund-Thomson syndrome are autosomal recessive genomic instability disorders associated with cancer predisposition and/or premature aging which involve mutations in genes encoding RecQ family helicasesenzymes responsible for maintenance of genome integrity [188]. Mutations in the $W R N$ gene give rise to Werner's syndrome, which characterized by many, but not all, of the features of the normal aging, including premature graying an thinning of the hair loss of skin elasticity, cataracts, type II diabetes mellitus, hypogonadism, osteoporosis, atherosclerosis and predisposition to malignancies, mainly to sarcomas [189]. Bloom's syndrome, a rare disorder associated with the $B L M$ gene mutation and pleiotropic phenotypes including immunodeficiency, impaired fertility, proportional dwarfism, sun-induced facial erythematic, and early development of cancers of all types [190]. In Rothmund-Thomson syndrome associated with mutations in the RECQ4 gene, affected patients show growth deficiency, photosensitivity with poikylodermatous skin changes, cataracts, early graying and loss of hair, as well as some increase in incidence of neoplasia, mainly osteogenic sarcomas [191]. Inherent genomic instability is main feature that links these three genetic disorders at cellular level and manifested in different chromosome abnormalities [188]. The $p 53 / W r n$ mice showed an acceleration of tumorigenesis and it was suggested a genetic interactions between $p 53$ and Wrn [192]. In normal human cells, the p53-WRN complex may recognize abnormal DNA structures such as stalled replication forks, leading either to a coordination of cell cycle and DNA repair events or to the induction of apoptosis [188].

Hutchinson-Gilford syndrome, or progeria, is a rare genetic disease with a number of features of premature senility: thinning of skin with loss of subcutaneous fat, loss of hair, marked growth retardation, the signs of atherosclerosis with involvement of heart and brain. Death occurs at a median age of 12 years [193]. There are no data on cancer incidence in the HutchinsonGilford syndrome patients. Among the genetic diseases associated with the defects of DNA repair, there are Cocayne's syndrome and ataxia telangiectasia considered to be segmental progeroid syndromes [193]. There is no reports on the increased frequency of cancer associated with Cocayne's syndrome, whereas in ataxia telangiectasia patients cancer incidence (mainly lymphomas and lymphocytic leukemia's) is increased about 1200 -fold over age-matched controls $[8,186]$.

Alongside with the classical progeria and partial progeria syndromes, some diseases are accompanied by disturbances which might be regarded as signs of the intensified aging. For example, the syndrome of SteinLeventhal (sclerocystic ovaries syndrome) occurs during puberty and is characterized by a bilateral sclerocystic enlargement of the ovaries, associated with a pronounced thickness of the capsule of the ovaries which forms a mechanical obstacle for the ovulatory rupture of a mature follicle. Follicular cysts and hyperplasia of theca tissue are found in such ovaries. Patients have anovulation, sterility, hirsutism, hyperlipidemia, lowered glucose tolerance, hyperinsulinemia, obesity, hypertension, and increased incidence of breast and endometrial cancer [11]. In rodents, the syndrome of persistent estrus, which normally completes the reproductive period of life, can be induced by several methods, including neonatal administration of sex steroids, exposure to some chemical carcinogens or to ionizing irradiation, housing under a constant light regime, subtotal ovariectomy, orthotopic transplantation of an ovary into castrated animals, electrolytic lesion of anterior and/or mediobasal hypothalamus, etc, [8]. Regardless of the method of the induction, premature aging and increase in tumor incidence have been observed in rats with persistent estrus [8].

The induction of persistent estrus in rats with chemical carcinogens (DMBA, NMU) was associated with increased tumor incidence when compared with animals without persistent estrus exposed to a carcinogen alone $[8,159,194]$. These observations suggest promoting effect of intensified aging processes observed in rats with persistent estrus syndrome on carcinogenesis. 
Table 4

Effect of aging rate modifications on tumor development in transgenic and mutant mice

\begin{tabular}{|c|c|c|c|c|}
\hline \multirow[t]{2}{*}{ Genetic modification, gene function } & \multirow[t]{2}{*}{ Effect on longevity } & \multicolumn{2}{|c|}{ Effect on tumor developmen $t$} & \multirow[t]{2}{*}{ References } \\
\hline & & Incidence & Latency & \\
\hline \multicolumn{5}{|l|}{ Accelerated aging } \\
\hline SAMP (senescent accelerated mouse) & Decreases $(<14$ mo. $)$ & No effect & Decreases & [207] \\
\hline nu/nu (athymic mice) & Decreases & No effect & Decreases & {$[208,209]$} \\
\hline$o b / o b$ (obese mice) & Decrease & Increase & Decreases & {$[210,211]$} \\
\hline$g c d$ (germ cell - deficient) & Ovarian senecsence & Increased & Decreased & [212] \\
\hline Klotho $\left(k l^{-l-}\right)$ & $<100$ days & No data & No data & [213] \\
\hline$h G H, b G H$ (growth hormone) overexpression & Decreases & Increases & Decreases & {$[214,215]$} \\
\hline$h G H$-releasing factor overexpression & Decreases & Increases & Decreases & [216] \\
\hline$X P A^{-I-}$ (DNA excision repair) & Decreases & No effect & No data & {$[217]$} \\
\hline Parp $^{-1-}$ (base excision and DNA strand break repair) & Decreases & $\begin{array}{l}\text { Increased susceptibility } \\
\text { to carcinogens }\end{array}$ & $\begin{array}{l}\text { Increased susceptibility } \\
\text { to carcinogens }\end{array}$ & {$[218]$} \\
\hline $\mathrm{Ku} 80^{-1-}$ (DNA double-strand break repair) & Decreases & Decreases & Decreases & [219] \\
\hline$K u 70^{-1-}$ (DNA double-strand break repair) & Decreases & Decreases & Decreases & {$[220]$} \\
\hline $\mathrm{Atm}^{-1-}$ (ataxia telangiectasia) & Decreases & Increases & Decreases & {$[221]$} \\
\hline$m T R^{-1-}$ (telomerase) & Decreases & Increases & Decreases & [201] \\
\hline K5-Tert (overexpression of telomerase) & Decrease & Increases & Decreases & [206] \\
\hline$L-m y c$ (oncogene, DNA binding) & Decreases & Increases & Decreases & [222] \\
\hline$H E R-2 /$ neu (oncogene, EGF receptor) & Decreases & Increases & Decreases & [223] \\
\hline$p 53^{-I-}$ (anti-oncogene, apoptosis) & Decreases & Increases & Decreases & {$[224]$} \\
\hline$p 53^{+I m}$ (anti-oncogene overexpression) & Decreases & Decreases & Decreases & {$[225]$} \\
\hline$C \times 32^{-1-}$ (connexin32; gap junction gene) & Decreases & Increases & Decreases & [226] \\
\hline \multicolumn{5}{|l|}{ Postponed aging } \\
\hline Ames dwarf mice & $+50-64 \%$ & No effect & Increases & [198] \\
\hline DWC3F1 dwarf mice & $+25-50 \%$ & Decreases & Increases & {$[227]$} \\
\hline$p 66^{\text {shc-1- }}$ (adaptor protein) & $+30 \%$ & No effect & No data & {$[228]$} \\
\hline$M G T M$ (DNA repair) & Increases & Decreases & No data & {$[200]$} \\
\hline$\alpha-M U P A$ (urokinase plasminogen activator) & Increases & No data & No data & {$[229]$} \\
\hline $\mathrm{grh}^{-1-}$ (growth hormone receptor) & Increases & No data & No data & {$[230]$} \\
\hline
\end{tabular}

\section{Effect of genetic modifications of aging on carcinogenesis}

Mutant and genetically modified animal models which are characterized by shortening or extension of the life span give a unique possibility to evaluate the role of aging genes in mechanisms of carcinogenesis [195]. Transgenic and null mutant ('knockout') animal models also offer an important opportunity to identify and study both carcinogens and chemopreventive agents $[196,197]$. The analysis of the available data on transgenic and mutant mice has shown that only few models represent examples of life span extension [195]. Ames dwarf mutant mice and $\mathrm{O}^{6}$-methylguanine-DNA methyltransferase (MGMT) transgenic mice live longer than wild-type strains [198-200]. As usual, the incidence of spontaneous tumors in these mice was similar to those in controls, whereas the latent period of tumor development was increased. Practically all models of accelerated aging (excepting $\mathrm{p} 53^{+/ m}$ mice) show the increased tumor incidence and shortening of tumor latency (Table 4).

The telomerase knockout mice provide an opportunity to understand the effects associated with critical telomere shortening at the level of organism. The survival of $m T R^{-1-}$ mice was decreased dramatically with age and increased incidence of spontaneous malignancies (mainly lymphomas and teratocarcinomas) was observed compared with their wild-type counterparts [201]. The analysis of the telomerase-deficient mouse model points to immunological defects as possible causes of the poor health and death of these mice [202]. Experiments in the telomerase-deficient mice have shown that in the setting of a compromised p53 pathway, telomere-based crisis can facilitate carcinogenesis by promoting chromosomal instability [203]. A recent study using telomerase-deficient mice has shown that differences in telomere length and regulation might impact dramatically on both the spectrum and cytogenetics of tumors during aging [204]. Re-introducing 
telomerase in late generation telomerase-deficient mice, Tert $^{-1-}$, which have short telomeres and shows severe proliferative defects, restores of telomerase activity followed by a rescue chromosomal instability and premature aging [205].

To evaluate the possible risks of telomerase expression in adult somatic tissues transgenic $\mathrm{K} 5$-Tert mice have been generated [206]. These mice overexpress telomerase in stratified epithelia and have a higher wound healing and increased incidence of spontaneous and induced by carcinogens tumors. The increased mortality and tumor incidence was more evident in $p 53^{+/-}$background, indicating that telomerase activity cooperates with $p 53$ deficiency in carcinogenesis. The authors stressed that although telomerase is not a potent oncogene, high levels of telomerase activity in normal somatic tissues results in a decreased life span an increased incidence of tumors as organism ages.

It is worthy to note that this phenomenon has been observed both in mice which display phenotype more resembling the natural aging and in mice showed only partial features of normal aging process. Why is the case? Certainly, aging predisposes cells to accumulate mutations some of which are necessary for initiation of tumorigenesis in target tissues [47,231].

Recent findings suggest that certain types of DNA damage and inappropriate mitogenic signals can also cause cells to adopt a senescent phenotype [17,18,232]. Cells respond to a number of potentially oncogenic stimuli by adopting a senescent phenotype. These findings suggest that the senescence response is a failsafe mechanism that protects cells from tumorigenic transformation. Despite the protection from cancer conveyed by cellular senescence and other mechanisms that suppress tumorigenesis, the development of cancer is almost inevitable as mammalian organisms age.

It was shown there were increased incidence as well as the age-related accumulation of chromosome aberrations in liver of short-living mouse strain A as compared with long-living C57L/6 mice [233]. Short-living BDF1, SAMP6/Tan and A/J mice showed a significant agerelated increase in spontaneous frequencies of micronucleated reticulocytes whereas long-living ddY, CD-1, B6C3F1, SAMR1, and MS/Ae did not show significant age-related differences in mean frequencies of spontaneous micronuclei [234]. Long-live mutant Ames dwarf mice and knockout $\mathrm{p} 66^{\text {she-1- }}$ mice were less vulnerable to oxidative damage than wild-type controls $[228,235]$, whereas senescence-prone strain, SAMP, had increased production of ROS [207], DNA damages and somatic mutation as compared with senescence-resistant SAMR strain [236]. MGMT-overexpressed mice are more resistant to alkylating agents [199,237], whereas deficient in DNA repair MGMT $^{-1-}$ and Parp ${ }^{-1-}$ mice are more susceptible to effect of alkylating chemicals and ionizing radiation [218,238]. No significant differences were found in the mutation spectra and the mutation incidence between $p 53^{-1-}$ and $p 53^{+1+}$ mice $[239,240]$, whereas the incidence of spontaneous tumors in $p 53^{-1-}$ mice were increased as compared with wild-type control [241,242]. Gap junction-deficient mice $\left(C \times 32^{-1-}\right)$ have an extremely increased susceptibility to spontaneous and chemically induced carcinogencsis [226]. Mice with a defect in the xeroderma pigmentosum group A $(X P A)$ gene have a complete deficiency in nucleotide excision repair and have a more than 1000 -fold higher risk to developing UV-induced skin cancer as well as increased susceptibility of internal organs to mutagenesis and development of cancer after exposure to chemical carcinogens $[217,243]$. However, the incidence of spontaneous tumors in these mice was relatively low-only $15 \%$ and tumors developed after the age of 18 months [217]. It is very important that the rate of accumulation of somatic mutations with age significantly varies in different tissues of mice [47,244-247].

Many benign or relatively well controlled tumors may also harbor many potentially oncogenic mutations, suggesting that the tissue microenvironment can suppress the expression of many malignant phenotypes $[14,18]$. Cellular senescence has been proposed to contribute to organismal aging. Senescent cells have recently been shown to accumulate with age in human tissues [14]. One possibility is that the tissue microenvironment is disrupted by the accumulation of dysfunctional senescent cells. Thus, mutation accumulation may synergies with the accumulation of senescent cells, leading to increasing risk for developing cancer. It is worthy of note, however, that discussing the difference in human and mouse telomere biology, the possibility was suggested that replicative senescence does not exist in the mouse [150].

Most cancer susceptibility genes were originally thought to control cell proliferation and death directly, acting as 'gatekeepers'. During last few years it has become clear that genes that maintain the integrity of the genome (DNA repair genes) are 'caretakers' and may be even more frequent causes of predisposition to cancer. Gatekeepers are genes that directly regulate the growth of tumors. Inactivation of a given gatekeeper gene leads to a very specific tissue distribution of cancer. In contrast, inactivation of a caretaker gene leads to genetic instabilities which result in increased mutation of all genes, including gatekeepers [44]. It is worthy to note that this classification is oversimplification of the real situation. For example, defects of DNA repair gene MSH2 result in a limited subset of colon cancer in humans. At the same time, defects in $p 53$ and $R b$ pathways arc present in $80-90 \%$ of all human cancers. At the same time the important role in tumor promotion and progression is played by genes involved in tissue metabolic and growth pathways and immune signaling gene, e.g. $G H, I G F-1, A P O E, T C R$, etc. These genes 


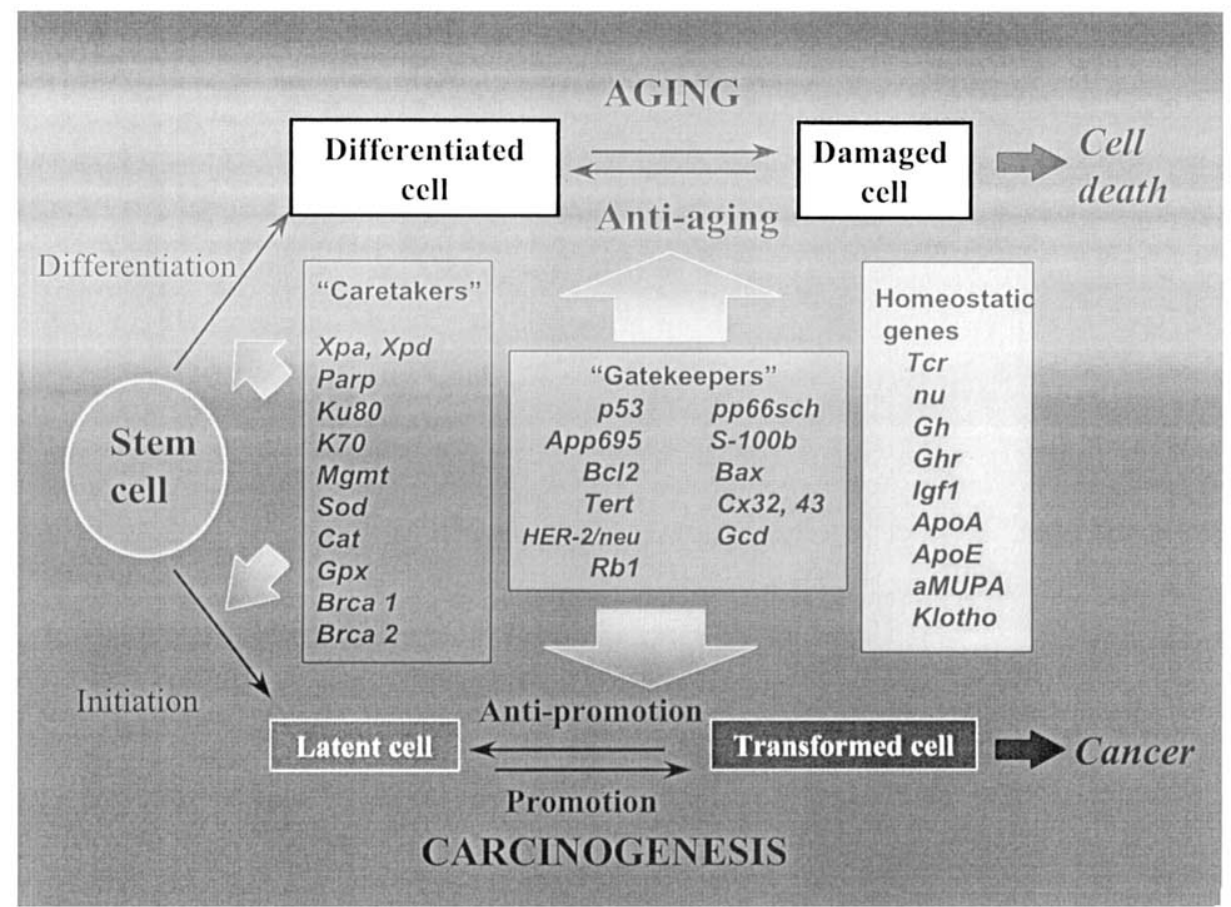

Fig. 4. Cellular targets of gene effects on aging and carcinogenesis ([195], with modifications). Stem cell can be drived by differentiation finally to terminal differentiation and to cell death or to be subjected to initiation and promotion under the influence of endogenous or exogenous carcinogenic stimuli. Caretaker and gatekeeper genes control both processes determining a tissue homeostasis and normal function of cell, tissue and organism. Homeostatic genes control mainly growth and progression of transformed cells. With age, the expression of some genes changed (see Fig. 5) and control of tissue homeostasis became less effective leading to an increase in cancer incidence.

act as 'homeostatic' genes. Available data have shown that all types of genes are involved in control of aging as well (Fig. 4). It is clear, that both aging and carcinogenesis are a complex multifactorial process that can have many causes. In that sense new transgenic and knockout mouse models with prolonged or reduced longevity will be an important instrument for evaluation the role of genes involved in aging in mechanisms of carcinogenesis.

A recent experiment by Tyner et al. [225] mice with truncated $p 53$ in one allele were genetically engineered $\left(p 53^{+/ m}\right)$. This mutation confers phenotypes consistent with activated $p 53$ function causing markedly reduced longevity with extensive signs of premature aging, including osteoporosis, generalized organ atrophy, impair wound healing, and diminished stress tolerance. It was noted that $p 53^{+/ m}$ mice typically died with no obvious signs of disease, and the cause of death was often difficult to determine. These unexpected observations suggest that $p 53$ activation can cause premature aging in at least a subset of mammalian tissues, whereas wild type $p 53$ contributes to normal aging. Most impressive finding was enhanced resistance of mutant $\left(p 53^{+/ m}\right)$ mice to spontaneous tumors compared with wild-type $\left(p 53^{+/+}\right)$. Authors noted that $p 53 \mathrm{~m}$-allele expression constructs enhance wild-type $p 53$ transacti- vation activity and can suppress cancer cell growth in the presence of wild-type $p 53$. The enhanced tumor resistance in $p 53^{+/ m}$ mice dependent on wild-type $p 53$, supporting a model in which the m-allele product requires wild-type $p 53$ to promote tumor suppression. The authors claim that the association of early aging and tumor resistance in mice consistent with the idea that senescence is a mechanisms of tumor suppression $[134,238,248,249]$. The paradox that overactive $p 53$ suppresses cancer but accelerates aging can be explained by the fact that cancer results from the malfunctioning of p53 in single cells, whereas aging involves a tissuewide process [250]. Cells with inactive $p 53$ ultimately shorten life span because, cancer develops, whereas cell with abnormally high $p 53$ activity do not contribute to cancer, but instead undergo cell death or senescence. With time, there changes may compromise tissue physiology, shortening life span through aging. Thus, p53 activity must be tightly controlled to balance a predisposition to cancer (too little $p 53$ ) and premature aging (too much p53) [250]. Another explanation of the $p 53^{+/ m}$ phenomena might be raised from the concept of phenoptosis (programmed death of multicellular organism) [251]. According to the hypothesis, aging represents a slow reactive oxygen species-linked programmed death of organisms eliminating individuals with damaged 
genomes and giving reproductive advantage to those who succeeded in a better preservation of their genomes from damage. Interesting a hierarchical model of epithelial cell generation supported by data on the rate of telomere shortening both in vivo and in vitro, and by data on the rate of synonymous substitutions in Ylinked, X-linked and autosomal genes in rodents, suggests that limiting the number of cell generations leads to a vast reduction in the risk of cancer and reduced the rate of aging [252].

\section{Oxidative stress in aging and carcinogenesis}

One of the most advanced theories of aging is free radical theory proposed by in 1956 by D. Harman $[58,59,253]$. This theory postulated that various oxidative reactions occurring in the organism (mainly in mitochondria) generate free radicals as byproduct which cause multiple lesions in macromolecules (nucleic acids, proteins and lipids), leading to their damage and aging. This theory explains not only the mechanism of ageing per second but also a wide variety of age-associated pathology, cancer including [59,251,253-256]. The recent evidence suggest that key mechanisms of both aging and cancer are linked via endogenous stress-induced DNA damage caused by reactive oxygen species. They include oxidative nuclear and mitochondrial DNA damage and repair, the telomere shortening and telomere-driven cellular senescence and have been intensively discussed in a number of comprehensive reviews [251,253-259]. It is worthy to note that some other aspects of the relationships between aging and cancer discussed in this review, e.g. chemically- and radiationinduced carcinogenesis, also are critically involved the free radical processes (for review see [254,260]; see also above the Section 4).

\section{Life span extension and risk of cancer}

The effects of factors or drugs that increase life-span (geroprotectors) on spontaneous tumor development may provide important clues to the interactions of aging and carcinogenesis. About 20 substances were suggested as life span extension means on the basis of different theories on mechanisms of aging $[8,58,59,261,262]$. The term geroprotector was introduced for such kind of substances [8,58,263-265]. It seems rather fortunate because it means 'defending from aging'. Contrary to geriatric drugs which are prescribing to the elderly people, the treatment with geroprotectors should be used at young and adult age. Being suggested on the current knowledge on factors and mechanisms or theories of aging these interventions in the aging process sometime were followed by some unfavorable effects.

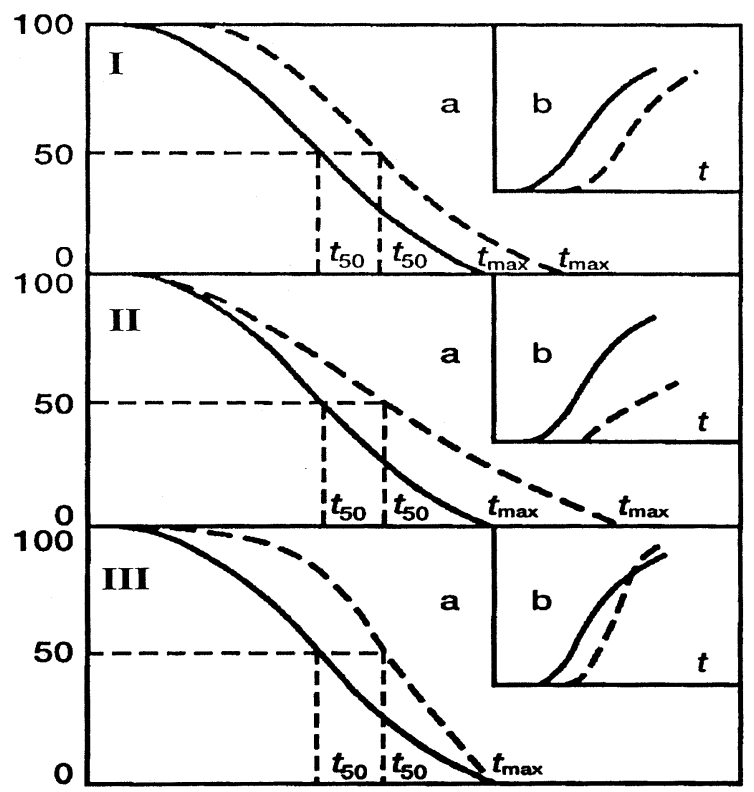

Fig. 5. Types of aging delay (a) and incidence of tumors (b) under influence of geroprotectors [7]. Ordinate, (a) number of survival animals, $\%$; (b) tumor incidence, \%. Abscissa, age. Solid line-control; broken line - administration of geroprotectors. The treatment with the type I geroprotector shifted to right both survival curve and tumor yield curve, thus increases the tumor latency. The treatment with the type II geroprotector slown down the rate of population aging leading to the decrease of tumor incidence and the increase of its latency. In the last case (III) the rate of population aging increases thus leading to the increase of cancer risk in the population.

The question of the safety of long-term use of these preparations including not only adverse effects but also the late effects, cancer including, is a one of the priority in this field. Another aspects of the problem related to observations on the age-related increase in cancer morbidity directly connected with the population aging $[1,2,13]$. Which is why the evaluation of possible risk of the increase in cancer incidence should be taken into account when means of life extension will be recommended to practical use. The comparison of the data on the mechanisms of action of geroprotectors with its influence on the development of spontaneous and experimentally induced tumors permits us to deepen our understanding of interactions between two fundamental biological processes-aging and carcinogenesis.

Life-span prolonging drugs and factors could be divided into three groups: (a) geroprotectors that prolong the life-span equally in all members of the population: these substances postpone the beginning of population aging; (b) geroprotectors that decrease the mortality of long-living subpopulation leading to a rise in maximal life-span: these substances slow down the population aging rate; (c) geroprotectors that increase the survival in short-living subpopulation without change of the maximal life-span: in this case aging rate increases (Fig. 5). 
Table 5

Effect of geroprotectors on tumor development in laboratory rodents [171]

\begin{tabular}{|c|c|c|c|c|c|c|c|}
\hline \multirow[t]{2}{*}{ Type of mortality delay } & \multirow[t]{2}{*}{ Geropotector } & \multirow[t]{2}{*}{ Species } & \multicolumn{2}{|c|}{ Life span } & \multicolumn{2}{|l|}{ Tumor } & \multirow[t]{2}{*}{ Reference } \\
\hline & & & Mean & Maximum & Latency & Incidence & \\
\hline \multirow[t]{4}{*}{ I } & 2-Mercaptoethylamine & Mouse & $\uparrow$ & $=$ & $\uparrow$ & $=$ & [266] \\
\hline & 2-Ethyl-6-methyl-3-oxipyridine & Mouse & $\uparrow$ & $=$ & $\uparrow$ & $=$ & [263] \\
\hline & Procaine (Gerovital) & Rat & $\uparrow$ & $=$ & $=$ & $=$ & [267] \\
\hline & Deprenyl & Rat & $\uparrow$ & $=$ & $\uparrow$ & $=$ & {$[268]$} \\
\hline \multirow[t]{7}{*}{ II } & Calorie restriction & Rat, mouse & $\uparrow$ & $\uparrow$ & $\uparrow$ & $\downarrow$ & [269] \\
\hline & Tryptophan-deficient diet & Rat & $\uparrow$ & $\uparrow$ & $\uparrow$ & $\downarrow$ & [270] \\
\hline & Antidiabetic biguanides & Rat, mouse & $\uparrow$ & $\uparrow$ & $\uparrow$ & $\downarrow$ & {$[8,271]$} \\
\hline & Phenytoin & Mouse & $\uparrow$ & $\uparrow$ & $\uparrow$ & $\downarrow$ & {$[8,271]$} \\
\hline & Succinic acid & Mouse & $\uparrow$ & $\uparrow$ & $\uparrow$ & $\downarrow$ & [8] \\
\hline & Thymalin, thymogen, vilon & Rat, mouse & $\uparrow$ & $\uparrow$ & $\uparrow$ & $\downarrow$ & {$[272-274]$} \\
\hline & Epithalamin, epitalon & Rat, mouse & $\uparrow$ & $\uparrow$ & $\uparrow$ & $\downarrow$ & {$[272,274]$} \\
\hline \multirow[t]{5}{*}{ III } & Selenium & Rat & $\uparrow$ & $=$ & $?$ & $\uparrow$ & {$[275]$} \\
\hline & EDTA-Na ${ }_{2}$ & Rat & $\uparrow$ & $=$ & $?$ & $\uparrow$ & [276] \\
\hline & Tritium oxid & Rat & $\uparrow$ & $=$ & $?$ & $\uparrow$ & {$[277]$} \\
\hline & Tocopherol (Vitamin E) & Rat & $\uparrow$ & $=$ & $\uparrow$ & $\uparrow$ & [278] \\
\hline & Melatonin & Mouse & $\uparrow$ & $=$ & $?$ & $\uparrow$ & [279] \\
\hline
\end{tabular}

Available data from the literature and our own studies show a good correlation between the type of geroprotectors and the pattern of tumor development in the same population of animals (Table 5) [8,261]. As can be seen in Table 5 and Fig. 5, geroprotectors of the first type do not influence the incidence of tumors but do prolong tumor latency. Geroprotectors of the second type are effective in inhibiting spontaneous carcinogenenesis, prolonging tumor latency, and decreasing tumor incidence. Drugs of the third type can sometimes increase the incidence of cancer $[8,261]$.

Thus, the use of growth hormone for elimination of wrinkles and prolongation of life-expectancy [280] may be associated with increased incidence of cancer [215,261]. In the multi-stage model of carcinogenesis, growth hormone promotes initiated and partially transformed cells and acts like a late-stage agent or tumor promoter.

The comparison of the data on the type of the slowing of mortality rate and the character of the antitumor effect of geroprotectors (Fig. 5) permits the suggestion that the tumor incidence of a certain age is the function of the rate of aging. We have found a highly significant positive correlation between the rates of mortality of the rat populations studied and the rates of age-related increase of tumor incidence in these populations [8]. Fig. 5 illustrates this conclusion. It may be seen that different types of the slowing of mortality may be associated with similar increases of mean life span. These results led to the conclusion that the incidence of tumors and the rate of their age-related increase directly depend upon the rate of mortality of a population no matter if the animals were exposed to geroprotector or not. This conclusion are in agreement with an observation that the genotype associated with increased survival in mice dying of cancer is also associated with a similar degree of life span extension in mice dying of other causes [281]. This dependence together with the data that environmental factors which promote tumor growth (overfeeding, constant illumination, chemical carcinogens, ionizing radiation, etc.) may cause an acceleration of aging suggests that the rate of mortality in these cases may be a function of the dose of carcinogenic agent.

In the framework of multi-stage carcinogenesis, geroprotectors may both inhibit and enhance the passage of transformed cells through sequential carcinogenic stages. In general, the efficacy of geroprotectors in preventing cancer development decreases inversely with the age of exposure to the carcinogen. It is important to emphasize that geroprotectors of the second type delay aging by influencing the 'main' regulatory systems of the organism (nervous, endocrine, immune). These effects delay the development of age-related changes in the microenvironment of cells exposed to carcinogens.

Geroprotectors may also be classified into two main groups according to their mechanism of action. The first group includes drugs that prevent stochastic lesions of macromolecules. The theoretical basis for using these drugs is provided for by variants of the 'catastrophe error' theory, which regards aging as a result of the accumulation of stochastic damages. The second group includes substances that appear to delay intrinsic aging.

Antioxidants are the most typical representatives of the first class of geroprotectors. Age at start of administration and doses of environmental carcinogens influence the geroprotective and tumor-preventing effects of antioxidants. The effectiveness of these substances increases when the initial administration occurs early in life and decreases with the dose of environmental carcinogen(s) to which the organism was exposed. 
The second class of geroprotectors includes antidiabetic biguanides (phenformin and buformin), the pineal peptide Epithalamin, melatonin and caloricrestricted diet. These factors influence the hormonal, metabolic and immunological functions of the body, delaying age-related changes in these functions $[8,261]$. It is worth noting that a difference between these two classes is rather conventional. There are evidence of clear protective effect of caloric restriction as well as melatonin and pineal peptides against damage of both DNA and proteins. Thus, it was suggested that caloric restriction retards cancer and aging by altering free radical metabolism [282] and by decrease in the incidence of age-related spontaneous mutations [283]. However, there are data on the absence of changes in the spontaneous mutation frequency or specificity in dietary restricted mice [284]. It was shown that melatonin is a most potent endogenous scavenger of free radicals in vitro and in vivo $[60,285]$. Melatonin inhibits production of DNA adducts in carcinogen-exposed animals [285], inhibits mutagenic and clastogenic effect of some chemical carcinogens [286], protects chromosomes of human lymphocytes from radiation damages [287] and enhances gap junctional intercellular communications in vitro [288]. The pineal peptide preparation epithalatmin stimulates synthesis and secretion of melatonin [289] and has antioxidant and lipid peroxidation inhibitory effects [290].

We believe that the data presented above permit consideration of possible causes of the increase in cancer incidence in the present century. The survival curves of human populations were noted to be more and more 'rectangular' [291]. This is caused first of all by the decrease in infant and early mortality which is connected with tuberculosis and other infectious and noninfectious diseases. As a result, a significant increase in the mean life span of the human population occurred. Maximum human life span, however, has stayed the same for centuries. Thus, the changes in the shapes of the survival curves of human populations respond to the third type of aging delay according to the classification of Emanuel and Obukhova [263] (see Fig. 5). The changes of this type were shown experimentally $[8,261]$ and epidemiologically [292] to be associated with an increase in rumor incidence. In other words, for the increase in mean life span achieved by the decrease in the mortality at early ages, mankind pay at later ages by an increased risk of having cancer or some other diseases of civilization like atherosclerosis or diabetes.

There are two strategies of stem cell which may be realized in an organism. One strategy is the cell differentiation and aging, and at least, in its individual death (apoptotic or necrotic) $[251,293]$. When factors of anti-aging reach some limit of their compensatory possibilities to support tissue and functional homeostasis in life-important organs, the death of an organ- isms as a whole take place. Another strategy of the stem cells in the circumstances of influence of exogenous or endogenous harmful factors could leads to its dedifferentiation, immortalization and formation of a clone of neoplastic cells [80,293] (Fig. 6). Both strategies are multi-stage processes, many steps of which are well characterized in relation to the process of carcinogenests $[8,13,77]$ (see also Figs. 1-4). However, the multi-stage pattern of aging needs serious studies and formalization $[172,294]$. It is worth of note, that multistage models of cellular aging and immortalization have been developed in an attempt to explain delayed genomic instability, in which initiation of carcinogenesis is linked not only to a direct increase in chromosomal aberrations and mutation rate of oncogencs and tumor suppressor genes, but also to enhanced levels of aberrations and mutation in distant progeny and a predisposition to immortalization $[172,295]$. In addition there have been multilevel models of carcinogenesis (examining the heterogeneous decrease in growth rate and accumulations of damages with age at the chromosome, cell, tissue and organism level) in which there was observed a convergence of findings related to cancer in culture and in the organism [296], The simplified scheme presented allows us to understand why drugs which prevent effects of some factors accelerating aging or, contrary, stimulate the anti-aging factors, in different way affecting homeostasis in tissues and in an organism as a whole, may promote or inhibit tumor development.

We believe that further progress in modern preventive medicine is impossible without radical changes in the approaches to public health and to the prolongation of the human life span. In the burst of industrialization, urbanization, and increasing environmental pollution, one may hope only for a partial alleviation of the unfavorable effects on human health. The achievement of significant results in this field will require the solution of very complex scientific and technical problems as well as considerable economic expense. It is probably true that even at present, changes in the life style, i.e. in dietary and sexual habits and in smoking and alcohol consumption, may be the most promising approach to achieving a decrease in cancer incidence and, hence, an increase in life span. It seems to become more and more clear that means which normalize the age-related changes in the hormonal status, metabolism, and immunity and thus slow down the realization of the genetic program of aging (not postpone aging, but decelerating the rate of it) must be most effective in the protection from aging and the prevention of cancer development. Among these means pineal peptide preparations Epithalamin [289,297] and peptide Epitalon (Ala-Glu-Asp-Gly) [274,298], calorie restriction or drugs mimic it, e.g. antidiabetic biguanides, sugar substitutes, and possible, anorhexants. The influences which protect from the initiating action of damaging agents (antiox- 


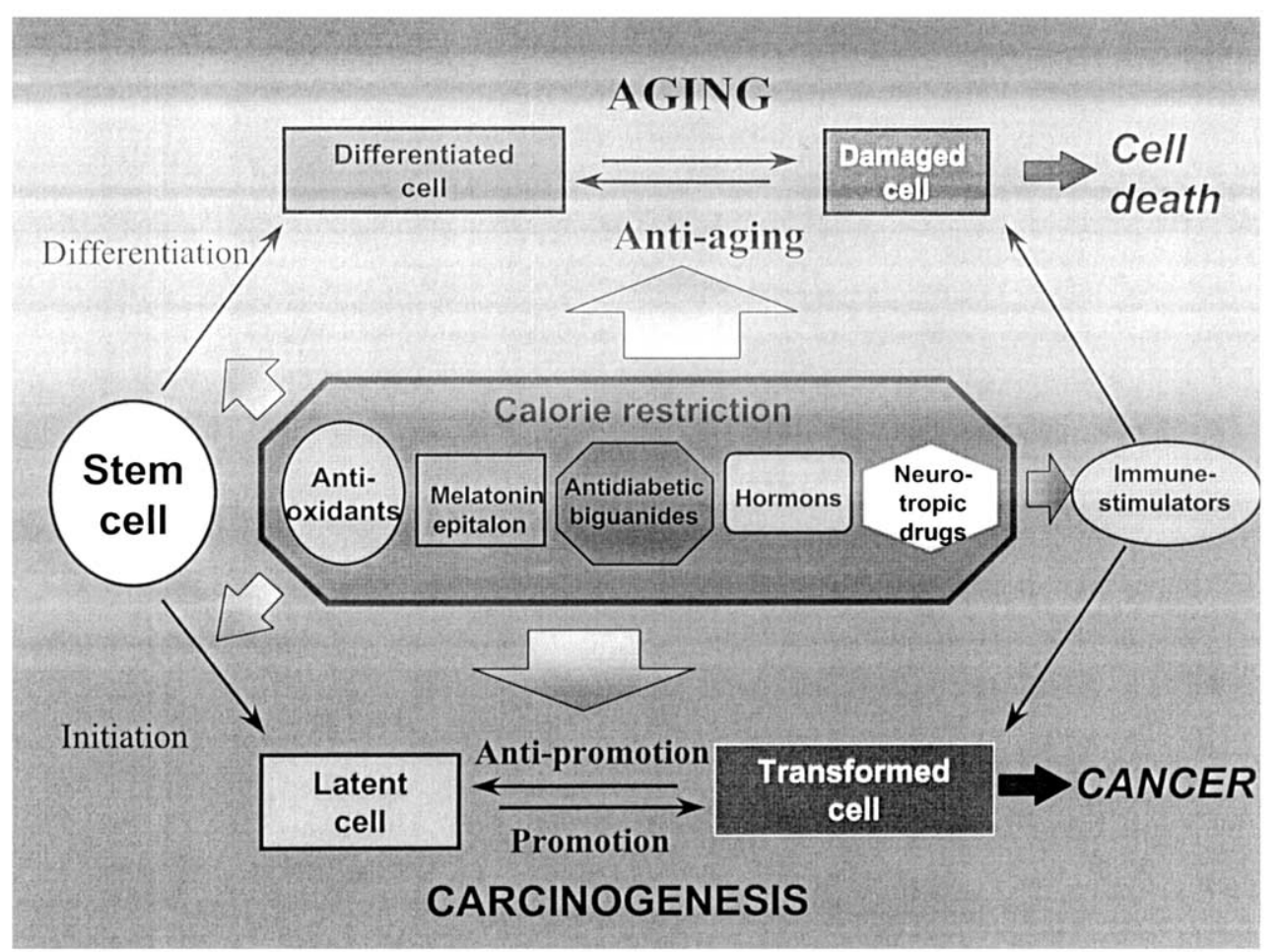

Fig. 6. Targets in the effects of geroprotectors on aging and cardnogenesis [261]. Calorie restriction is the best way to delay both aging and cancer, affecting genes controlling these processes. Antioxidants, some hormones, peptides and drugs in this or that degree are mimetes of calorie restriction. Thus, the problem of adequate and safe treatment with geroprotectors is critical for healthy aging and prevention of age-associated diseases, cancer including.

idants and antimutagens) may be important additional means of prophylaxis and accelerated aging especially under conditions of an increased risk of exposure to environmental harmful agents. Generally speaking, antioxidants and antimutagens work as inhibitors of time-dependent processes in the organism, whereas calorie restricted diet, antidiabetic biguanides and pineal peptide preparations influence mainly age-dependent processes in the organism [299]. Table 6 presents global view on gene expression profile of aging based on data recently published [300-304] and suggested effect on the same profile of carcinogenesis and some geroprotectors. Although available data are scarce or absent, it seems that only few geroprotectors involves genetic mechan-

Table 6

Gene expression profile of aging: hypothetical effect of geroprotectors [261]

\begin{tabular}{|c|c|c|c|c|c|}
\hline & Stress response & Energy metabolism & Neuronal injury & Biosynthesis & Cancer \\
\hline Aging & $\uparrow$ & $\downarrow$ & $\uparrow$ & $\downarrow$ & $\uparrow$ \\
\hline Carcinogenesis & $\uparrow$ & $\downarrow$ & $\uparrow$ & $\uparrow$ & $\uparrow$ \\
\hline \multicolumn{6}{|c|}{ Effect of geroprotectors } \\
\hline Caloric restriction & $\downarrow$ & $\uparrow$ & $\downarrow$ & $\uparrow$ & $\downarrow$ \\
\hline Antioxidants & $\downarrow$ & $?$ & $\downarrow(\uparrow)$ & $?$ & $\downarrow(\uparrow)$ \\
\hline Deprenyl & $\downarrow$ & $?$ & $\downarrow$ & $?$ & $\downarrow$ \\
\hline Phenormin & $\downarrow$ & $\uparrow$ & $\downarrow$ & $?$ & $\downarrow$ \\
\hline L-DOPA & $\downarrow$ & $?$ & $\downarrow(\uparrow)$ & $?$ & $\downarrow$ \\
\hline Succinic acid & $\downarrow$ & $\uparrow$ & $\downarrow$ & $?$ & $\downarrow$ \\
\hline Melatonin & $\downarrow$ & $?$ & $\downarrow$ & $?$ & $\uparrow$ \\
\hline Pineal peptides & $\downarrow$ & $\uparrow$ & $\downarrow$ & $\uparrow$ & $\downarrow$ \\
\hline
\end{tabular}

Adapted from [300-304]. 
isms in its anti-aging effects. The study of these mechanisms should be a priority for gerontological research in this century.

\section{Conclusions}

The incidence of cancer increases with age in humans and in laboratory animals alike, but patterns of agerelated distribution of tumors are different for different tissues and different tumors. Aging may increase or decrease the susceptibility of different tissues to tumor initiation and usually facilitates promotion and progression of carcinogenesis. It has been found that some common genetic changes (e.g. activated telomere maintenance) known to occur in carcinogenesis have a key role in the immortalization process [14,305-307]. Three major hypotheses, and non mutually exclusive hypotheses may explain the association of cancer and age:

- Carcinogenesis is a time-consuming process, whose final product, cancer, is more likely to occur in person of advanced age depending on accumulation of the dose to the environmental carcinogen(s).

- Aging tissues undergo molecular changes that parallel early carcinogenic changes and prime these tissues to the effects of carcinogens.

- Age-related changes in body microenvironment, including proliferative and immune-senescence may favor cancer development and growth.

It was suggested that the telomere instability linking aging and increased cancer risk. Increased susceptibility to the effects of tumor promoters is found both in aged animals and aged humans, as predicted by the multistage model of carcinogenesis. Old animals should be included in standard protocol for the long-term assay for carcinogenicity, in particular, of compounds with suggested tumor-promoting activity. Strategies for cancer prevention must include not only measures to minimize exposure to exogenous carcinogenic agents, but also measures to normalize the age-related alterations in internal milieu. Life span prolonging drugs (geroprotectors) may either postpone population aging and prolong tumor latency or decrease the mortality in long-living individuals in populations and inhibit carcinogenesis. At least some geroprotectors may increase the survival of short-living individuals in populations but increase the incidence of malignancy.

\section{Reviewers}

Thomas von Zglinicki, Department of Gerontology, Wolfson Research Centre, Institute for the Health of the elderly Newcastle General Hospital, Westgate Road, Newcastle upon Tyne NE4 6BE, UK.

Linda S. Birnbaum, National Health and Environmental Effects Research Laboratory, United States Environmental Protection Agency, Research Triangle Park, NC 27711-2055, USA.

Irmgard Irminger, Biology of Aging Laboratory and Chief, Therapeutic Monitoring Laboratory, Department of Geriatrics, University of Geneva, Chemin du Petit Bel Air 2, CH-1225 Chêne-Bourg/Geneva, Switzerland.

\section{Acknowledgements}

This paper was written in the framework of the project 'Cancer Rates Over Age, Time, and Place' at the Max-Planck Institute for Demographic Research, Rostock, Germany, and was supported in part by grant \# 01-04-07007 from the Russian Foundation for Basic Research. The author is very thankful to James W. Vaupel for the opportunity to use the facilities of the Max Planck Institute for Demographic Research to complete this paper, Lodovico Balducci (Moffitt Cancer Center, Tampa, FL), Jan Vijg (Univerisy of Texas Health Science Center, San Antonio, TX), Anatoli I. Yashin (Max-Planck Institute for Demographic Research, Rostock), Mark A. Zabezhinski (N.N. Petrov Research Istittue of Oncology, St. Petersburg) for the criticism and valuable recommendations.

\section{References}

[1] Dix D, Cohen P. On the role of aging in carcinogenesis. Anticancer Res 1999;19:723-6.

[2] Parkin DM, Bray FI, Devesa SS. Cancer burden in the year 2000. The global picture. Eur J Cancer 2001;37:S4-S66.

[3] Peto R, Roe FJC, Lee PN, Levy L, Clack J. Cancer and ageing in mice and men. Br J Cancer 1975;32:411-26.

[4] Peto R, Parish SE, Gray RG. There is no such thing as ageing, and cancer is not related to it. In: Likhachev A, Anisimov V, Montesano R, editors. Age-related factors in carcinogenesis, vol. 58. Lyon, France: IARC, 1985:43-53.

[5] Peto J. Cancer epidemiology in the last century and the next decade. Nature 2001;411:390-5.

[6] Peto R, Doll R. There is no such thing as aging. Br J Med 1997;315:1030-2.

[7] Anisimov VN. Carcinogenesis and aging. Adv Cancer Res 1983;40:265-324.

[8] Anisimov VN. Carcinogenesis and aging, vol. 1-2. Boca Raton, FL: CRC Press, 1987.

[9] Anisimov VN. Age-related mechanisms of susceptibility to carcinogenesis. Semin Oncol 1989;16:10-9

[10] Miller RA. Gerontology as oncology. Cancer 1991;68:2496-501.

[11] Dilman VM. Development, aging, and disease. A new rationale for and intervention strategy. Switzerland: Chur: Harwood Acad Publ, 1994.

[12] Simpson AJG. A natural somatic mutation frequency and human carcinogenesis. Adv Cancer Res 1997;71:209-40. 
[13] Anisimov VN. Age as a factor of risk in multistage carcinogenesis. In: Balducci L, Lyman GH, Ershler WB, editors. Comprehensive geriatric oncology. Amsterdam: Harwood Academic Publishers, 1998:157-78.

[14] DePinho RA. The age of cancer. Nature 2000;408:248-54.

[15] Fernandez-Pol JA, Douglas MG. Molecular interactions of cancer and age. Hematol/Oncol Clin North Am 2000;14:25-44.

[16] Rubin H. Selected cell and selective microenvironment in neoplastic development. Cancer Res 2001;61:799-807.

[17] Campisi J. Aging and cancer: the double-edged sword or replicative senescence. J Am Geriatr Soc 1997;45:1-6.

[18] Campisi J. Cancer, aging, and cellular senescence. In Vivo 2000;14:183-8.

[19] Campisi J, Kirn S, Lim CS, Rubio M. Cellular senescence, cancer and aging: the telomere connection. Exp Gerontol 2001;36:1619-37.

[20] Krtolica A, Parincllo S, Lockett S, Desprez P-Y, Campisi J. Senescent fibroblasts promote epithelial cell growth and tumorigenesis: a link between cancer and aging. Proc Natl Acad Sci USA 2001;98:12072-7.

[21] Rinehart CA, Torti VR. Aging and cancer: the role of stromal interactions with epithelial cells. Mol Carcinogen 1997;18:18792.

[22] Tomatis L, editor. Cancer: causes, occurrence and control. IARC science publication number 100. Lyon: IARC, 1990.

[23] Montesano R, Hall J. Environmental causes of human cancers. Eur J Cancer 2001;8(Suppl.):67-87.

[24] Ward JM. Background data and variations in tumor rates $\mathrm{f}$ control rats and mice. Prog Exp Tumor Res 1983;26:241-58.

[25] Dix D, Cohen P, Flannery J. On the role of aging in cancer incidence. J Theor Biol 1980;83:163-73.

[26] Pompei F, Polkanov M, Wilson R. Age distribution of cancer in mice: the incidence turnover at old age. Toxicol Ind Health 2001;17:7-16.

[27] Lipman RD, Dallal GE, Bronson RT. Lesion biomarkers of aging in $\mathrm{B} 6 \mathrm{C} 3 \mathrm{~F} 1$ hybrid mice. $\mathrm{J}$ Gerontol Med Sci 1999;54A:466-77.

[28] Lipman RD, Dallal GE, Bronson RT. Effect of genotype and diet on age-related lesions in ad libitum fed and calorie-restricted F344, BN, and BNF3F1 rats. J Gerontol Med Sci 1999;54A:478-91.

[29] Smith DWE. Cancer mortality at very old ages. Cancer 1996;77:1373-6.

[30] Bordin P, Da Gol PG, Peruzzo P, Stanta G, Guralnik JM, Cattin L. Causes of death and clinical diagnostic error in extreme aged hospitalized people: a retrospective clinical-necropsy survey. J Gerontol Med Sci 1999;54A:M554-9.

[31] Miyaishi O, Ando F, Matsuzawa K, Kanawa R, Isobe K. Cancer incidence in old age. Mech Ageing Dev 2000;117:47-55.

[32] Pompei F, Wilson R. Age distribution of cancer: the incidence turnover at old age. Hum Ecol Risk Assessment 2001;7:1619-50.

[33] Anisimov VN. Effect of age on dose-response relationship in carcinogenesis induced by single administration of $N$-nitrosomethyrurea in female rats. J Cancer Res Clin Oncol 1988;114:628-35.

[34] Biclas JH, Heddle JA. Proliferation is necessary for both repair and mutation in transgenic mouse cells. Proc Natl Acad Sci USA 2000;97:11391-6.

[35] Thompson TA, Haag JD, Gould MN. ras gene mutations are absent in NMU-induced mammary carcinomas from aging rat. Carcinogenesis 2000;21:1917-22.

[36] Birnbaum LS. Pharmacokinetic basis of age-related changes in sensitivity to toxicants. Annu Rev Pharmacol Toxicol 1991;31:101-28.

[37] Anisimov VN, Birnbaum LS, Butenko GM, et al. Principles for evaluating chemical effects on the aged population, environmental health criteria, vol. 144. Geneva: WHO, 1993.
[38] Mayersohn M. Pharmacokinetics in the elderly. Environ Health Perspect 1994;102(Suppl 11):119-24.

[39] Preston-Martin S, Pike MC, Ross RK, Jones PA, Henderson BE. Increased cell division as a cause of human cancer. Cancer Res 1990;50:7415-21.

[40] Hanahan D, Weinberg RA. The hallmarks of cancer. Cell 2000;100:57-70.

[41] Evan G, Littlewood T. A matter of life and cell death. Science 1998;281:1317-21.

[42] Green DR, Evan GI. A matter of life and death. Cancer Cell 2002;1:19-30.

[43] Zhang Y, Herman B. Ageing and apoptosis. Mech Ageing Dev 2002;123:245-60.

[44] Kinzler KW, Vogelstein B. Gatekeepers and caretakers. Nature 1997;386:761-3.

[45] Lindahl T. Instability and decay of the primary structure of DNA. Nature 1993;362:709-15.

[46] Pitot HC. The molecular biology of carcinogenesis. Cancer 1993;72:962-70

[47] Vijg J. Somatic mutations and aging: a re-evaluation. Mutat Res 2000;447:117-35.

[48] Luzatto L. The mechanisms of neoplastic transformation. Eur $\mathbf{J}$ Cancer 2001;37:S114-7.

[49] Matoha HF, Cosgrove JW, Atak JR, Rapoport SL. Selective elevation of c-myc transcript levels in the liver of the aging Fischer-344 rat. Biochem Biophys Res Commun 1987;147:1-7.

[50] Ono T, Uehara Y, Kurishita A, Tawa R, Sakurai H. Biological significance of DNA methylation in the aging process. Age Aging 1993;22:534-43.

[51] Catania J. Fairweather DS. DNA methylation and cellular aging. Mutat Res 1991;256:283-93.

[52] Yu BP, editor. Free radicals in aging. Boca Raton: CRC Press, 1993.

[53] Shigenaga MK, Hagen TV, Ames BN. Oxidative damage and mitochondrial decay in aging. Proc Natl Acad Sci USA 1994;91:10771-8

[54] Barja G. Endogenous oxidative stress: relation to aging, longevity and caloric restriction. Ageing Res Rev 2002;1:397-411.

[55] Du MQ, Carmichael PL, Phillips DH. Induction of activated mutations in the human c-Ha-ras proto-oncogene by oxygen free radicals. Mol Carcinogenen 1994;11:170-5.

[56] Fraga CG, Shigenaga MK, Park J-W, Degan P, Ames BN. Oxidative damage to DNA during aging 8-hydroxy2 'deoxyganosine in rat organ DNA and urine. Proc Natl Acad Sci USA 1990;87:4533-7.

[57] Ames BN, Shigenaga MB, Hagen TM. Oxidants, antioxidants, and the degenerative diseases of aging. Proc Natl Acad Sci USA 1993;90:7915-22.

[58] Harman DH. Free-radical theory of aging: increasing the functional life span. Ann New York Acad Sci 1994;717:257-66.

[59] Harman DH. Extending functional life span. Exp Gerontol 1998;33:95-112.

[60] Reiter RJ. Reactive oxygen species, DNA damage, and carcinogenesis: intervention with melatonin. In: Bartsch $\mathrm{C}$, Bartsch $\mathrm{H}$, Blask DE, Cardinali DP, Hrushesky WJM, Mecke D, editors. The pineal gland and cancer neuroimmunoendocrine mechanisms in malignancy. Berlin: Springer, 2001:442-55.

[61] Coller HA, Khrapko K, Bodyak ND, Nekhaeva E, HerreroJimenez P, Thilly WG. High frequency of homoplasmic mitochondrial DNA mutations in human tumors can be explained without selection. Nat Genet 2001;28:147-50.

[62] Coller HA, Bodyak ND, Khrapko K. Frequent intracellular clonal expansions of somatic mtDNA mutations. Ann New York Acad Sci 2002;959:434-47.

[63] Nekhaeva E, Bodyak ND, Kraytsberg Y, et al. Clonally expanded mtDNA point mutations are abundant in individual cells of human tissues. Proc Natl Acad Sci USA 2002;99:5521-6. 
[64] Bodyak ND, Nekhaeva E, Wei JY, Khrapko K. Quantitation and sequencing of somatic deleted mtDNA in single cells: evidence for partially duplicated mtDNA in aged human tissues. Hum Mol Genet 2001;10:17-24.

[65] de Grey AD. The reductive hotspot hypothesis: an update. Arch Biochem Biophys 2000;373:295-301.

[66] Ouhtit A, Ueda M, Nakazawa H, Ichihashi M, Dumaz N, Sarasin A, Yamasaki H. Quantitative detection of ultravioletspecific p53 mutations in normal skin from Japanese patients. Cancer Epidemiol Biomark Prev 1997;6:433-8.

[67] Liang SB, Ohtsuki Y, Furihata M, Takeuchi T, Iwata J, Chen $\mathrm{BK}$, Sonobe H. Sun-expoure-and aging-dependent p53 protein accumulation results in growth advantage for tumor cells in carcinogenesis of nonmelanocytic skin cancer. Virchows Arch 1999;434:193-9.

[68] Chow M, Rubin H. Clonal selection versus genetic instability as the driving force in neoplastic transformation. Cancer Res 2000;60:6510-8.

[69] Anisimov VN, Gvardina OE. $N$-Nitrosomethylures-induced carcinogenesis in the progeny of male rats of different ages. Mutat Res 1995;316:139-45.

[70] Hemminki K, Kyyronen P. Parental age and risk of sporadic and familial cancer in offspring: implications for germ cell mutagenesis. Epidemiology 1999;10:747-51.

[71] Hemminki K, Kyyronen P, Vaittinen P. Parental age as a risk factor of childhood leukemia and brain cancer in offspring. Epidemiology 1999;10:271-5.

[72] Dockerty JD, Draper G, Vincent T, Rowan SD, Bunch KJ. Case-control study of parental age, parity and socioeconomic status in relation to childhood cancers. Int $\mathrm{J}$ Epidemiol 2001;30:1428-37.

[73] Walter CA, Intano CW, McCarrey JR, McMahan CA, Walter RB. Mutation frequency declines during spermatogenesis in young mice but increases in old mice. Proc Natl Acad Sci USA 1998;95:10015-9.

[74] Risch N, Reich EW, Wishnick MM, McCarthy JG. Spontaneous mutation and parental age in humans. Am J Hum Genet 1987;41:218-48.

[75] Dolle ME, Snyder WK, Dunson DB, Vijg J. Mutational fingerprints of aging. Nucleic Acids Res 2002;30:545-9.

[76] Consensus report. In: Vanio H, Magee PN, McGregor D, McMichael AJ editors. Mechanisms of carcinogenesis in risk identification. IARC science publication number 116. Lyon, IARC, 1992, p. 9-56.

[77] Moolgavkar S, Krewski D, Zeise L, Cardis E, Moller H, editors. Quantitative estimation and prediction of human cancer risk. IARC science publication number 131. Lyon: IARC, 1999.

[78] Simons JW. Genetic, epigenetic, dysgenetic and non-genetic mechanisms in tumorigenesis, II. Further delineation of the rate limiting step. Anticancer Res 1999;19:4781-9.

[79] Ponten J. Cell biology of precancer. Eur J Cancer 2001;37:S97S113.

[80] Reya T, Morrison SJ, Clarke MF, Weissman IL. Stem cells, cancer, and cancer stem cells. Nature 2001;414:105-11.

[81] Schlessinger D, Van Zant G. Does functional depletion of stem cells drive aging. Mech Ageing Dev 2001;122:1537-53.

[82] Aboseif S, El-Sakka A, Young P, Cunha G. Mesenchymal reprogramming of adult human epithelial differentiation. Differentiation 1999;65:113-8.

[83] Liotta LA, Kohn EC. The microenvironment of the tumor-host interface. Nature 2001;411:375-9.

[84] Li Y, Liu W, Hayward SW, Cunha G, Baskin LS. Plasticity of the urothelial phenotype: effects of gastro-intestinal mesenchyme/stroma and implications for urinary tract reconstruction. Differentiation 2000;66:126-35.

[85] Stenback F, Peto R, Shubik P. Initiation and promotion at different ages and doses in 2200 mice. III. Linear extrapolation from high doses may underestimate low-dose tumor risks. Br $\mathbf{J}$ Cancer 1981;44:24-34.

[86] Ebbesen P. Papilloma development on TPA treated young and senescent mouse skin. In: Likhachev A, Anisimov V, Montesano $\mathrm{R}$, editors. Age-related factors in carcinogenesis. IARC science publication number 58. Lyon: IARC, 1985:167-71.

[87] Hennings H, Boutwell RK. Studies on the mechanism of skin tumor promotion. Cancer Res 1970;30:312-20.

[88] Kruszewski FH, Conti CJ, DiGiovanni J. Characterization of skin tumor promotion and progression by chrysarobin in SENCAR mice. Cancer Res 1987;47:3783-90.

[89] Hennings D, Yuspa SH. Two-stage tumor promotion in mouse skin: an alternative interpretation. J Natl Cancer Inst 1985;74:735-40.

[90] Moriwaki S, Ray S, Tarone RE, Kraemer KH, Grossman L. The effect of donor age on the processing of UV-damaged DNA by cultured human cells: reduced DNA repir capacity and increased DNA mutability. Mutat Res 1996;364:117-23.

[91] Wei Q. Effect of aging on DNA repair and skin carcinogenesis: a minireview of population-based studies. J Invest Dermatol Symp Proc 1998;3(1):19-22.

[92] D'Errico M, Calcagnile AS, Corona R, et al. p53 mutations and chromosome instability in basal cell carcinomas developed at an early or late age. Cancer Res 1997;57:747-52.

[93] Ueda M. Telomerase in cutaneous carcinogenesis. J Dermatol Sci 2000;23(Suppl 1):S37-40.

[94] Boutwell RK. Some biological aspects of skin carcinogenesis. Prog Exp Tumor Res 1964;4:207-50.

[95] Roe FJC, Carter RL, Mitchley R, Peto R, Hecker E. On the persistence of tumor initiation and the acceleration of tumor progression in mouse skin tumorigenesis. Int $\mathrm{J}$ Cancer 1972;9:264-73.

[96] Van Duuren BL, Sivak A, Katz C, Steidman I, Melchionne S. The effect of aging and interval between primary and secondary treatment in two-stage carcinogenesis on mouse skin. Cancer Res 1975;35:502-5.

[97] Battalora MStJ, Spadling JW, Szczesniak CJ, et al. Agedependent skin tumorigenesis and transgene expression in the Tg.AC (v-Ha-ras) transgenic mice. Carcinogenesis 2001;22:6519.

[98] Lee G-H, Sawada N, Mochizuki Y, et al. Immortal epithelial cells of normal $\mathrm{C} 3 \mathrm{H}$ mouse liver in culture: possible precursor populations for spontaneous hepatocellular carcinoma. Cancer Res 1989;49:403-9.

[99] Ogawa K, Onoe T, Takeuchi M. Spontaneous occurrence of gamma glutamyl transpeptidase-positive hepatocytic foci in 105week-old Wistar and 72-week-old Fischer 344 male rats. J Natl Cancer Inst 1981;67:407-12.

[100] Ward JM, Lynch P, Riggs C. Rapid development of hepatocellular neoplasms in aging male $\mathrm{C} 3 \mathrm{H} / \mathrm{HeNcr}$ mice given phenobarbital. Cancer Lett 1988;39:9-18.

[101] Kraupp-Grasl B, Huber W, Taper H, Schulte-Hermann R. Increased susceptibility of aged rats to hepatocarcinogenesis by the peroxisome proliferator nafenopin and the possible involvement of altered liver foci occurring spontaneously. Cancer Res 1991;51:666-71

[102] Ward JM. Increased susceptibility of liver of aged F.344/Ncr rats to the effects of phenobarbital on the incidence, morphology, and histochemistry of hepatocellular foci and neoplasms. J Natl Cancer Inst 1983;71:815-23.

[103] Ebbesen P. Reticulosarcoma and amyloid development in $\mathrm{BALB} / \mathrm{c}$ mice inoculated with syngeneic cells from young and old donors. J Natl Cancer Inst 1971;47:1241-5.

[104] Geschickter CF. Mammary carcinoma in the rats with metastasis induced by estrogen. Science 1939;89:35-9. 
[105] Geschickter CF, Byrnes EW. Factor influencing the development and time of appearance of mammary cancer in the rat in response to estrogen. Arch Pathol 1942;33:334-42.

[106] Carrilo MC, Favre C, Carnovale CE, et al. Involvement of $\mu$, class glutathione $S$-transferase subunit $\mathrm{M}_{2}\left(\mathrm{rGST} \mathrm{M}_{2}\right)$ levels in the initiation and promotion of hepatocarcinogenesis in old rats. Exp Gerontol 2001;36:255-65.

[107] Reuber MD, Glover EL. Hyperplastic and early neoplastic lesions of the liver in Buffalo strain rats of various ages given subcutaneous carbon tetrachloride. J Natl Cancer Inst 1967;38:891-7.

[108] Anisimov VN, Sheiko EV, Zhukovskaya NV. Effect of age on development of tumors in the intrasplenic ovarian grafts in ovariectomized rats. J Cancer Res Clin Oncol 1992;119:111-6.

[109] Anisimov VN. Age and dose-dependent carcinogenic effects of $N$-nitrosomethylurea administered intraperitoneally in a single dose to young and adult female mice. J Cancer Res Clin Oncol 1993;119:657-64.

[110] Anisimov VN. Effect of aging and interval between primary and secondary treatment in carcinogenesis induced by neonatal exposure to 5-bromodeoxyuridine and subsequent administration of $N$-nitrosomethylurea in rats. Mutat Res 1995;316:17387.

[111] Anisimov VN. Aging and the mechanisms of carcinogenesis: some practical implications. J Exp Clin Cancer Res 1998; 17:263-8.

[112] Takahashi M, Nishimura S, Miyajima K, Sasahara K, Yoshida M, Ando J, Maekawa A. Time-dependent promotion activity of $17 \beta$-estradiol on uterine carcinogenesis in mice initiated with $\mathrm{N}$ ethyl- $N$-nitrosourea. Cancer Lett 2001;165:123-30.

[113] Backman V, Wallace MB, Perelman LT, et al. Detection of preinvasive cancer cells. Nature 2000;406:35-6.

[114] Summerhayes IC, Franks LM. Effect of donor age on neoplastic transformation of adult bladder epithelium in vitro. J Natl Cancer Inst 1979;62:1017-23.

[115] Kunisada T, Banner D, Friedman V, Schneider EL. Incerased susceptibility to SV40 transformation with development and in vitro aging. Exp Cell Res 1990;189:222-6.

[116] Nettesheim P, Topping DC, Jamasbi R. Host and environmental factors enhancing carcinogenesis in the respiratory tract. Annu Rev Pharmacol Toxicol 1981;21:133-63.

[117] Ershler WB. Mechanisms of age-associated reduced tumor growth and spread in mice. In: Balducci L, Lyman GH, Ershler WB, editors. Geriatric oncology. Springfield: Lippincott, 1992:76-85.

[118] Ershler WB. Explanations for reduced tumor proliferative capacity with age. Exp Gerontol 1992;27:551-8.

[119] Miller RA. Aging and cancer - another perspective. J Gerontol 1993;48:B8-9.

[120] Anisimov VN, Zhukovskaya NV, Loktionov AS, et al. Influence of host age on lung colony forming capacity of injected rat rhabdomyosarcoma cells. Cancer Lett 1988;40:77-82.

[121] Anisimov VN, Zhukovskaya NV, Loktionov AS, et al. Host and donor age dependency of colony forming capacity of lung-affine rat rhabdomyosarcoma RA-2 cells. Abstract of the international conference on tumor micro environment: progression, therapy and prevention. Tiberias, Israel, 1995, p. 6.

[122] McCullough KD, Coleman WB, Smith GJ, Grisham JW. Agedependent regulation of the tumorigenie potential of neoplastically transformed rat liver epithelial cells by me liver microenvironment. Cancer Res 1994;54:3668-71.

[123] Hayflick L. How and why we age. Exp Gerontol 1998;33:63953.

[124] Wei W, Sedivy JM. Differentiation between senescence (M1) and crisis (M2) in human fibroblast culture. Exp Cell Res 1999;253:519-22.
[125] Dimri G, Lee X, Basile G, et al. A bio-marker that identifies senescent human cells in culture and in aging skin in vivo. Proc Natl Acad Sci USA 1995;92:9363-7.

[126] Yegorov YE, Akimov SS, Mass R, Zelenin AV, Prudovsky IA. Endogenous $\beta$-galactosidase activity in continuously nonproliferating cells. Exp Cell Res 1998;243:207-11.

[127] Shay JW, Pereira-Smith OM, Wright WR. A role of both Rb and $\mathrm{p} 53$ in the regulation of human cellular senescence. Exp Cell Res 1991;196:33-9.

[128] Shay JW, Wright WR. Quantitation of the frequency of immortalization of normal human diploid fibroblasts by SV40 large T antigen. Exp Cell Res 1989;184:109-18.

[129] Cristofalo VJ, Allen RG, Pignolo RJ, Martin BG, Beck JC. Relationship between donor age and the replicative lifespan of human cells in culture: a revaluation. Proc Natl Acad Sci USA 1998;95:10614-9.

[130] Schmitt CA, Fridman JS, Yang M, Lee S, Baranov E, Hoffman RM, Lowe SW. A senescence program controlled by p53 and pl $6^{\mathrm{INK} 4 \mathrm{a}}$ contributes to the outcome of cancer therapy. Cell 2002;109:335-46.

[131] Macicra-Coelho A. Neoplastic disease through the human life span. Biogerontology 2001;2:179-92.

[132] Macicra-Coelho A. Genome reorganization through cell division, implications for aging of the organism and cancer development. Ann New York Acad Sci 1994;719:108-28.

[133] Tavoloni N, Inoue H. Cellular aging is a critical determinant of primary cell resistance to $\mathrm{v}-s r c$ transformation. J Virol 1997;71:237-47.

[134] Serrano M, Lin AW, McGurrach ME, Beach D, Lowe SW. Oncogenic ras provokes premature cell senescence associated with accumulation of p53 and pl6 ${ }^{\mathrm{INK} 4 \mathrm{a}}$. Cell 1997;88:593-602.

[135] Bringold F, Serrano M. Tumor supressors and oncogenes in cellular senescence. Exp Gerontol 2000;35:317-29.

[136] Shelton DN, Chang E, Whittier PS, Choi D, Funk WD. Microarray analysis of replicative senescence. Curr Biol 1999;9:939-45.

[137] Shay JW, Wright WE, Werbin H. Loss of telomeric DNA during aging may predispose cells to cancer (review). Int J Oncol 1993;3:559-63.

[138] Reddel RR. A reassessment of the telomere hypothesis of senescence. Bioessays 1998;20:977-84.

[139] Cemi C. Telomere, telomerase, and myc. An update. Mutat Res 2000;462:31-47

[140] Takubo K, Izumiyama-Shimomura N, Honma N, et al. Telomere length are characteristic in each human individual. Exp Gerontol 2002;37:523-31.

[141] Blagosklonny MV. How carcinogens (or telomere dysfunction) induce genetic instability: associated-selection model. FEBS Lett 2001;506:169-72.

[142] Wynford-Thomas D, Bond JA, Wyllie FS, Jones CJ. Does telomere shortening drive selection for p53 mutation in human cancer. Mol Carcinogen 1995;12:119-23.

[143] Mathon NF, Malcolm DS, Harrisingh MC, Cheng L, Lloyd AC. Lack of replicative senescence in normal rodent glia. Science 2001;291:872-5.

[144] Hampel B, Unterluggauer H, Jansen-Durr P, Erdel M. Agerelated polyploidization and cell death in senescent human epithalial cells. First Conference on Functional Genomics of Aging, April 24-27, 2002. Seville, Spain, 2002. p. 41.

[145] Tang DG, Tokumoto YM, Apperly JA, Lloyd AC, Raff MC. Lack of replicative senescence in cultured rat oligodendrocyte precursor cell. Science 2001;291:868-71.

[146] Romanov SR, Kozakiewicz BK, Holst CR, Stampfer MR, Haupt LM, Tisty TD. Normal human mammary epithelial cells spontaneously escape senescence and acquire gcnomic changes. Nature 2001;409:633-7. 
[147] Clevenger CV. A old epithelial cell never dies, it just agonesces away. Trends Endocrinol Metab 2001;12:183-4.

[148] Rha SY, Park KH, Kim TS, et al. Changes of telomerase and telomere length in paried normal and cancer tissues of breast. Int J Oncol 1999;15:839-45.

[149] Sasaki M, Honda T, Yamada H, Wake N, Barret JC, Oshimura M. Evidence for multiple patways to cellular senescence. Cancer Res 1994;54:6090-3.

[150] Wright WE, Shay JW. Telomere dynamics in cancer progression and prevention: fundamental differences in human and mouse telomere biology. Nat Med 2000;6:849-51.

[151] Xie HQ, Hu VW. Modulation of gap junction in senescent endothelial cells. Exp Cell Res 1994;214:172-6.

[152] Cameron IL. Minimum number of cell doubling in an epithelial cells population during the lifespan of the mouse. J Gerontol 1972;27:157-61.

[153] Potten M, Loeffler M. Stem cells: attributes, cycles, spirals, pitfalls and uncertainties lessons for and from the crypt. Development 1990;110:1001-20.

[154] Rubin H. Cell aging in vivo and in vitro. Mech Ageing Dev 1997;98:1-35.

[155] Buetow DE. Cellular content and cellular proliferation changes in the tissues and organs of the aging mammals. In: Cameron IL, Thrasher JD, editors. Cellular and molecular renewal in the mammalian body. New York: Academic Press, 1971:87-105.

[156] Baserga RL. Cell division and the cell cycle. In: Finch CE, Hayflick L, editors. Handbook of the biology of aging. New York: Van Nostrand Reinholdd, 1977:101-21.

[157] Larionov LF. Cancer and endocrine system. Leningrad: Meditsina, 1938.

[158] Ohno S, Nagai Y. Genes in multiple copies as the Primary cause of aging. In: Bergsma D, Harrison DE, Paul NW, editors. Genetic effects of aging. New York: Alan R Liss, 1978:501-14.

[159] Anisimov VN. Blastomogenesis in persistent estrus rats. Vopr Onkol 1971;8:67-75.

[160] Teramoto S, Fukuchi Y, Uejima Y, Teramoto K, Orimo H. Influences of chronic tobacco smoke inhalation on aging and oxidant-antioxidant balance in the senescent-accelerated mouse (SAM)-P/2. Exp Gerontol 1993;28:87-95.

[161] Sacher GA. Life table modification and life prolongation. In: Finch CE, Hayflick L, editors. Handbook of the biology of aging. New York: Van Nostrand Reinhold, 1977:582-638.

[162] Alexandrov SA. Late radiation oathology of mammals. Fortschritte der Onkologie, band 6. Berlin: Akademik-Verlag, 1982.

[163] Golostchapov PV, Boitsova VP, Vorobjeva MI. Comparative analysis of effectiveness of chronic external irradiation at different daily doses. Moscow: Central Research Institute Atominform, 1988.

[164] Moskalev YI. Late effects of ionizing irradiation. Moscow: Meditsina, 1991.

[165] Anisimov VN, Zhukova OV, Beniashvili DS, Bilanishvili VG, Menabde MZ. Effect of light deprivation and electromagnetic fields on mammary carcinogenesis in female rats. Adv Pineal Res 1994;7:231-6.

[166] Stevens RG, Wilson BW, Anderson LE. The melatonin hypothesis. Breast cancer and use of electric power. Columbus: Battele Press, 1997.

[167] Brainard GC, Kaver R, Kheifets LI. The relationship between electromagnetic field and light exposure to melatonin and breast cancer risk: a review of the relevant literature. J Pineal Res 1999;26:65-100.

[168] Nikitina VM. Effect of modulated electromagnetic fields induced by marine radio transmitters on aging of the organism. Proceedings of international confrence on shipbuilding ISC. October 8-12, 1994. St. Petersburg, 1994. Sect. F:60-66.

[169] Singer M, Berg P. Genes and genomes: a changing perspective. Mill Valley, CA: University Science Books, 1991.
[170] Morris SH. The genetic toxicology of 5-bromodeoxyuridine in mammalian cells. Mutat Res 1991;258:161-88.

[171] Lindahl T. DNA repair enzymes. Ann Rev Biochem 1982;51:6187.

[172] Butov AA, Volkov MA, Anisimov VN, Sehl M, Yashin AI. A model of accelerated aging induced by 5-bromodeoxyuridine. Biogerontology 2002;3:175-82.

[173] Anisimov VN, Osipova GY. Effect of neonatal exposure to 5bromo-2'-deoxyuridine on life span, estrus function and tumor development in rats - an argument in favor of the mutation theory of aging. Mutat Res 1992;275:97-110.

[174] Anisimov VN. Carcinogenesis induced by neonatal exposure to various doses of 5-bromo-2'-deoxyuridine in rats. Cancer Lett 1995;91:63-71.

[175] Craddock VM. Shortening of the life span caused by administration of 5-bromodeoxyuridine to neonatal rats. Chem-Biol Interact 1981;35:139-44.

[176] Ward JM, Henneman JR, Osipova GY, Anisimov VN. Persistence of 5-bromo-2'-deoxyuridine in tissues of rats after exposure in early life. Toxicology 1991;70:345-52.

[177] Tapscott SJ, Lassar AB, Davis RL, Weintraub H. 5-Bromo-2' deoxyuridine blocks myogencsis by extinguishing expression of MyoD1. Science 1989;245:532-53.

[178] Weghorst CM, Henneman JR, Ward JH. Dose response of hepatic and DNA synthesis rates to continuous exposure of bromodeoxyuridine (BrdU) via slow-release-pellets or osmotic minipumps in male $\mathrm{B} 6 \mathrm{C} 3 \mathrm{~F} 1$ mice. $\mathrm{J}$ Histochem Cytochem 1991;39:177-82.

[179] Napalkov NP, Anisimov VN, Likhachev AJ, Tomatis L. 5bromodeoxyuridine-induced carcinogenesis and its modification by persistent estrus syndrome, unilateral nephrectomy, and Xirradiation in rats. Cancer Res 1989:49:318-23.

[180] Anisimov VN. The sole DNA damage induced by bromodeoxyuridine is sufficient for initiation of both aging and carcinogenesis in vivo. Ann New York Acad Sci 1994;719:494-501.

[181] Michishita E, Nakabayashi K, Suzuki T, et al. 5-bromodeoxyuridine induces senescence-like phenomena in mammalian cells regardless of cell type or species. J Biochem 1999;125:1052-9.

[182] Suzuki T, Minagawa S, Michishita E, Oginom H, Fujii M, Mitsui Y, Ayusawa D. Induction of senescence-associated genes by 5-bromodeoxyuridine in HeLa cells. Exp Gerontol 2001;36:465-74.

[183] Suzuki T, Yagunuma M, Oishi T, Michishita E, Ogino H, Fujii M, Ayusawa D. 5-Bromodeoxyuridine suppresses position effect variegation of transgenes in $\mathrm{HeLa}$ cells. Exp Cell Res 2001;266:53-63.

[184] Suzuki T, Iwata T, Minagawa S, Michishita E, Fujii M, Ayusawa D. Large-scale screening for senescence-associated genes with 5-bromodeoxyuridine and immortal cell lines. First conference on functional genomics of aging, April 24-27, 2002, Seville, Spain, 2002. p. 12.

[185] Mikhelson VM. Diseases of DNA repair and their relation with carcinogenesis and aging. Moscow: All-Union Institute for Medical Information, 1983.

[186] Lehmann AR. Ageing, DNA repair of radiation damage and carcinogenesis: fact and fiction. In: Likhachev A, Anisimov V, Montesano R, editors. Age-related factors in carcinogenesis, IARC science publication number 58. Lyon: IARC, 1985. p. 203-214.

[187] Bohr VA. Human premature aging syndromes and genomic instability. Mech Ageing Dev 2002;123:987-93.

[188] Mohaghegh P, Hickson ID. DNA helicase deficiencies associated with cancer predisposition and remature ageing disorders. Hum Mol Genet 2001;10:741-6

[189] Shen JC, Loeb LA. The Werner syndrome gene: the molecular basis of RecQ helicase-dcficiency diseases. Trends Genet 2000;16:213-20. 
[190] German J. Bloom's syndrome. Dermatol Clin 1995;13:7-18.

[191] Vennos EM, James WD. Rothmund-Thompson syndrome. Dermatol Clin 1995;13:143-50.

[192] Lebel M, Cardiff RD, Leder P. Tumorigenic effect of nonfunctional $\mathrm{p} 53$ or $\mathrm{p} 21$ in mice mutant in the Werner syndrome helicase. Cancer Res 2001;61:1816-9.

[193] Martin GM. Genetic syndromes in man with potential relevance to the pathobiology of aging. In: Bergsma D, Harrison DE editors. Genetic effects on ageing. Alan R Liss, New York, 1978. p. $5-19$.

[194] Alexandrov VA, Popovich IG, Anisimov VN, Napalkov NP. Influence of hormonal disturbances on transplacental and multigeneration carcinogenesis. In: Napalkov NP, Rice JM, Tomatis L, Yamasaki H, editors. Perinatal and multigeneration carcinogenesis. IARC science publication number 96, Lyon: IARC, 1989. p. 35-50.

[195] Anisimov VN. Mutant and genetically modified mice as models for studying the relationship between aging and carcinogenesis. Mech Ageing Dev 2001;122:121-1255.

[196] Alexander J. Use of transgenic mice in identifying chemopreventive agents. Toxicol Lett 2000;112/113:507-12.

[197] Gulezian D, Jacobson-Kram D, McCullough CB, et al. Use of transgenic animals for carcinogenicity testing: considerations and imlications for risk assessment. Toxicol Pathol 2000;28:48299.

[198] Bartke A, Brown-Borg H, Mattison J, Kinney B, Hauck S, Wright C. Prolonged longevity of hypopituitary mice. Exp Gerontol 2001;36:21-8.

[199] Walter CA, Grabowski DT, Street KA, Conrad CC, Richardson A. Analysis and modulation of DNA repair in aging. Mech Ageing Dev 1997;98:203-22.

[200] Qin X, Zhang S, Matsukuma S, Zarkovic M, Shimizu S, Ishikawa T, Nakatsuru Y. Protection against malignant progression of spontaneously developing liver tumors in transgenic mice expressing $\mathrm{O}^{6}$-methylguanine-DNA methyltransferase. Jpn J Cancer Res 2000;91:1085-9.

[201] Rudolph KL, Chang S, Lee HW, Blasco M, Gottlieb GJ, Greider C, DePinho RA. Longevity, stress response, and cancer in aging telomerase-deficient mice. Cell 1999;96:701-12.

[202] Blasco MA. Immunosenescence phenotypes in the telomerase knockout mouse. Springer Semin Immunopathol 2002;24:75-85.

[203] Artandi SE, DePinho RA. Mice without telomerase: what can they teach us about human cancer. Nat Med 2000;6:852-5.

[204] Artandi SE, Chang S, Lee L, Alson S, Gottlieb GJ, Chin L, DePinho RA. Telomere dysfunction promotes non-replicative translations and epithelial cancers in mice. Nature 2000;406:641-5.

[205] Samper E, Flores JM, Blasco MA. Restoration of telomerase activity rescues chromosomal instability and premature aging in Terc $^{-1-}$ mice with short telomeres. EMBO Reports 2001;2:800-7.

[206] Gonzalez-Suarez E, Flores JM, Blasco MA. Decreased viability with age and increased spontaneous tumor incidence in transgenic mice overexpressing telomerase. First conference /on functional genomics of aging, April 24-27, 2002, Seville, Spain, 2002, p. 37.

[207] Takeda T. Senescence-accelerated muse (SAM): a biogerontological resource in aging research. Neurobiol Aging 1999;20:10510.

[208] Sharkey FE, Fogh J. Incidence and pathological features of spontaneous tumors in athymic nude mice. Cancer Res 1979;39:833-9.

[209] Shisa H, Kojima A, Hiai H. Accelerating effect of nude gene heterozygocity on spontaneous AKR thymic lymphomagenesis. Jpn J Cancer Res 1986;77:568-71.
[210] Harrison DE, Archer JR, Astle CM. Effects of food restriction on aging: separation of food intake and adiposity. Proc Natl Acad Sci USA 1984;82:1835-8.

[211] Waxler SH, Brecher G, Beal SL. The effect of fat-enriched diet on the incidence of spontaneous mammary tumors in obese mice. Proc Soc Exp Biol Med 1979;162:365-8.

[212] Duncan MC, Chada KK. Incidence of tubulostromal adenoma of the ovary in aged germ cell-deficient mice. J Comp Pathol 1993;109:13-9.

[213] Kuro-o M, Matsumura Y, Aizawa H, et al. Mutation of the mouse klotho gene leads to a syndrome resembling ageing. Nature 1997;390:45-51.

[214] Wolf E, Kahnt E, Ehrlein J. Effects of long-term elevated serum levels of growth hormone on life expectancy of mice: lessons from transgenic animal models. Mech Ageing Dev 1993;68:7187.

[215] Bartke A. Growth hormone and aging. Endocrine 1998;8:103-8.

[216] Asa SL, Kovacs K, Stefaneanu L, Horvath E, Billestrup N, Conzalez Manchon C, Vale W. Pituitary mammosomatotroph adenomas develop in old mice transgenic for growth hormonereleasing hormone. Pros Soc Exp Biol Med 1990;193:323-5.

[217] Van Steeg H, Klein H, Beems RB, van Kreijl CF. Use of DNA repair-deficient XPA transgenic; mice in short-term carcinogenicity testing. Toxicol Pathol 1998;26:742-9.

[218] Masutani M, Nozaki T, Nakamoto K, et al. The reponse of Rarp knockout mice against DNA damaging agents. Mutat Res 2000;462:159-66.

[219] Vogel H, Lim DS, Karsenty G, Finegold M, Hasty P. Deletion of Ku86 causes early onset of senescence in mice. Proc Natl Acad Sci USA 1999;96:10770-5.

[220] Gu Y, Seidi KJ, Rathbun GA, et al. Growth retardation and leakey SCID phenotype of Ku70-deficient mice. Immunity 1997;7:653-65.

[221] Barlow C, Hirotsune S, Paylor R, et al. Atm-deficient mice: a paradigm of ataxia tclangiectasia. Cell 1996;86:159-71.

[222] Moroy T, Fischer PE, Lee G, Achacoso P, Wiener F, Alt FW. High frequency of myelomonocytic tumors in aging E-mu L-myc transgenic mice. J Exp Med 1992;175:313-22.

[223] Baturin DA, Akimova IN, Anisimov VN, et al. The effect of light regimen and melatonin on the development of spontaneous mammary tumors in HER-2/neu transgenic mice is related to a downregulation of HER-2/neu gene expression. Neuroendocrinol Lett 2001;22:439-45.

[224] Donchower LA, Harvey M, Vogel H, et al. Effects of genetic backgroun on tumorigenesis in p53-deficient mice. Mol Carcinogenesis 1995;14:16-22.

[225] Tyner SD, Venkatachalam S, Choi J, et al. Mutant mice that display early aging-associated phenotypes. Nature 2002;415:4553.

[226] Temme A, Buchmann A, Gabriel HD, Nelles E, Schwarz M, Willecke K. High incidence of spontaneous and chemically induced liver tumors in mice deficient for connexin32. Curr Biol 1997;7:713-6.

[227] Flurkey K, Papaconstantinou J, Harrison DE. The Snell dwarf mutation Pit ${ }^{d w}$ can increase life span in mice. Mech Ageing Dev 2002;123:121-30.

[228] Migliaccio E, Giorgio M, Mele S, et al. The p66 ${ }^{\text {shr }}$ adaptor protein controls oxidative stress response and life span in mammals. Nature 1999;402:309-13.

[229] Miskin R, Masos T, Yahav S, Shinder D, Globerson A. AlphaMUPA mice: a transgenic model for increased life span. Neurobiol Aging 1999;20:555-64.

[230] Coschigano KT, Clemmons D, Bellush LL, Kopchick JJ. Assessment of growth parameters and life span of GHR/BP gene-disrupted mice. Endocrinology 2000;141:2608-13.

[231] Lengauer C, Kinzler KW, Vogelstein B. Genetic instabilities in human cancers. Nature 1998;396:643-9. 
[232] Campisi J. Between Scilla and Charibdis: p53 links tumor suppression and aging. Mech Ageing Dev 2002;123:567-73.

[233] Crowley C, Curtis HJ. The development of somatic mutations in mice with age. Proc Natl Acad Sci USA 1963;49:625-8.

[234] Sato S, Taketomi M, Nakajima M, et al. Effect of aging on spontaneous micronucleus frequencies in peripheral blood of nine mouse strains. Mutat Res 1995;338:51-7.

[235] Brown-Borg HM, Rakoczy SG. Catalase expression in delayed and premature aging mouse models. Exp Gerontol 2000;35:199212.

[236] Hosokawa M, Fujisawa H, Ax S, Zahn-Daimler G, Zahn RK. Age-associated DNA damage is accelerated in the senescenceaccelerated mice. Mech Ageing Dev 2000;118:61-70.

[237] Allay E, Veigl M, Gerson SL. Mice over-expressing human $\mathrm{O}^{6}$ alkylguanine-DNA alkyltransferase selectively reduce $\mathrm{O}^{6}$ methylguanine mediated carcinogenic mutations to threshold levels after $N$-methyl- $N$-nitrosourea. Oncogene 1999;18:3783-7.

[238] Glassner BJ, Weeda G, Allan JM, et al. DNA repair methyltransferase (Mgmt) knockout mice are sensitive to the lethal effects of chemotherapeutic alkylating agents. Mutagenesis 1999;14:339-47.

[239] Nishino H, Knoll A, Buettner VL, Frisk CS, Maruta Y, Haavik J, Sommer SS. p53 wild-type and p53 nullizygous Big Blue transgenic mice have similar frequencies and patterns of observed mutation in liver, spleen and brain. Oncogene 1995; 11:263-70.

[240] Buettner VL, Nishino H, Haavik J, Knoll A, Hill K, Sommer SS Spontaneous mutation frequencies and spectra in p53 $(+/+)$ and p53((//) mice: a test of the 'guardian of the genome' hypothesis in the Big Blue transgenic mouse mutation detection system. Mutat Res 1997;379:13-20.

[241] Hursting SD, Perkins SN, Haies DC, Ward JM, Phang JM. Chemoprevention of spontaneous tumorigenesis in p53-knockout mice. Cancer Res 1995;55:3949-53.

[242] Atardi LD, Jacks T. The role of p53 in tumor suppression: lessons from mouse models. Cell Mol Life Sci 1999;55:48-63.

[243] Van Steeg H, Mullenders LHF, Vijg J. Mutagenesis and carcinogenesis in nucleotide excision repair-deficient XPA knock out mice. Mutat Res 2000;450:167-80.

[244] Dolle MET, Giese H, Hopkins CL, Martus HJ, Hausdorff JM, Vijg J. Rapid accumulation of genome rearrangements in liver but not in brain of old mice. Nature Genet 1997;17:431-4.

[245] Dolle MET, Snyder WK, Gossen JA, Lohman PHM, Vijg J. Distinct spectra of somatic mutations accumulated with age in mouse heart and small intestine. Proc Natl Acad Sci USA 2000;97:8403-8.

[246] Ono T, Ikehata H, Nakamura S, et al. Age-associated increase of spontaneous mutant frequency and molecular nature of mutation in newborn and old lacZ-transgenic mouse. Mutat Res 2000;447:165-77.

[247] Stuart GR, Oda Y, de Boer JG, Glickman BW. Mutation frequency and specificity with age in liver, bladder and brain of LacI transgenic mice. Genetics 2000;154:1291-300.

[248] Sager R. Senescence as a mode of tumor suppression. Environ Health Perspect 1991;93:59-62.

[249] Itahana K, Dimitri G, Campisi J. Regulation of cellular senescence by p53. Eur J Biochem 2001;268:2784-91.

[250] Ferbeyre G, Lowe SW. Ageing: the price of tumor suppression? Nature 2002;415:26-7.

[251] Skulachev VP. The programmed death phenomena, aging, and the Samurai law of biology. Exp Gerontol 2001;36:995-1024.

[252] Morris JA. The kinetics of epithelial cell generation: its relevance to cancer and aging. J Theor Biol 1999;199:87-95.

[253] Hamilton ML, Van Remmen H, Drake JA, et al. Does oxidative damage to DNA increase with age. Proc Natl Acad Sci USA 2001;98:10469-74.
[254] Kawanishi S, Hiraki Y, Oikawa S. Mechanism of guaninespecific DNA damage by oxidative stress and its role in carcinogenesis and aging. Mutat Res 2001;488:65-76.

[255] Salvioli S, Bonafe M, Capri M, Monti D, Fransceschi C. Mitochondria, aging and longevity-a new perspective. FEBS Lett 2001;492:9-13.

[256] von Zglinicki T, Burkle A, Kirkwood TBL. Stress, DNA damage and aging-an integrative approach. Exp Gerontol 2001;36:104962.

[257] Saretzki G, Sitte N, Merkel U, Wurm RE. Telomere shortening triggers a p53-dependent cell cycle arrest via accumulation of Grich single stranded DNA fragments. Oncogene 1999;18:514858.

[258] von Zglinicki T, Pilger R, Sitte N. Accumulation of single-strand breaks is the major cause of telomere shortening in human flbroblasts. Free Radical Biol Med 2000;28:64-74.

[259] Proctor CJ, Kikwood TBL. Modelling telomere shortening and the role of oxidative stress. Mech Ageing Dev 2002;123:351-6.

[260] Anisimov VN. Melatonin and colon carcinogenesis. In: Bartsch $\mathrm{C}$, Bartsch H, Blask DE, et al, editors. The pineal gland and cancer, neuroimmunoendocrine mechanisms in malignancy. Berlin: Springer, 2001:240-58.

[261] Anisimov VN. Life span extension and cancer risk: myths and reality. Exp Gerontol 2001;36:1101-36.

[262] Frolkis VV, Muradian KK. Life span prolongation. Boca Raton, FL: CRC Press, 1992.

[263] Emanuel LM, Obukhova LK. Types of experimental delay in aging patterns. Exp Gerontol 1975;13:25-9.

[264] Lipman RD. The prolongation of life: a comparison of antioxidants and geroprotectors versus superoxide in human mitochondria. J Gerontol 1981;36:550-7.

[265] Ghuji S. Pharmacology of aging process. In: I. Zs-Nagy, D. Harman, K. Kitani, editors. Methods of assessment and potential interventions. Ann New York Acad Sci 1994;717.

[266] Harman D. Free radical theory of aging: dietary implications. Am J Clin Nutr 1972;25:839-43.

[267] Asian A, Vrabiescu A, Domilescu D, Campeanu L, Costiniu M, Stanescu S. Long term treatment with procaine (gerovital H3) in albino rats. J Gerontol 1965;20:1-8.

[268] Kitani K, Minami C, Isobe K, Maechara K, Kanai S, Ivy GO, Carillo MC. Why (-)deprenyl prolongs survival of experimental animals: increase of anti-oxidant enzymes in brain and other body tissues as well as mobilization of various humoral factors may lead to systemic anti-aging effects. Mech Ageing Dev 2002;123:1087-100.

[269] Weindruch R, Walford R. The retardation of aging and disease by dietary restriction. Sprinfield, IL: C.C. Thomas, 1988.

[270] Segall PE, Timiras PS. Patho-physiologic findings after chronic tryptophan deficiency in rats; a model for delayed growth and aging. Mech Ageing Dev 1976;5:109-24.

[271] Dilman VM, Anisimov VN. Effect of treatment with phenformin, diphenylhydantoin, or L-DOPA on life span and tumor incidence in C3H/Sn mice. Gerontology 1980;26:241-5.

[272] Anisimov VN, Khavinson VK, Morozov VG. Carcinogenesis and aging. IV. Effect of low-molecular-weight factors of thymus, pineal gland and anterior hypothalamus on immunity tumor incidence and life span of $\mathrm{C} 3 \mathrm{H} / \mathrm{Sn}$ mice. Mech Ageing Dev 1982;19:245-58.

[273] Anisimov VN, Khavinson VK, Morozov VG. Immunomodulatory synthetic dipeptide 1-Glu-l-Trp slows down aging and inhivits spontaneous carcinogenesis in rats. Biogerontology 2000; $1: 55-9$

[274] Anisimov VN, Khavinson VK, Mikhalski AI, Yashin AI. Effect of synthetic thymic and pineal peptides on biomarkers of ageing, survival and spontaneous tumor incidence in female CBA mice. Mech Ageing Dev 2001;122:41-68. 
[275] Cherkes LA, Aptekar SG, Volgarev MN. Liver tumors induced by selenium. Bull Exp Biol Med 1962;53(3):78-83.

[276] Dubina TL, Razumovich AN. Introduction in experimental gerontology. Minsk: Nauka i Tekhnika, 1975.

[277] Muksinova KN, Voronin VS, Kirillova EN, et al. Late effects of chronic exposure to tritium oxide. In: Moskalev YI, editor. Biologic effects of low-level radiation. Moscow: Institute of Biophysics, 1983:70-7.

[278] Porta EA, Joun NS, Nitta RT. Effect of the type of dietary fat at two levels of vitamine $\mathrm{E}$ in Wistar male rats during development and aging, I. Life span serum biochemical parameters and pathological changes. Mech Ageing Dev 1980;13:1-39.

[279] Anisimov VN, Zavarzina NY, Zabezhinski MA, et al. Melatonin increases both life span and tumor incidence in female CBA mice. J Gerontol Biol Sci 2001;56A:B311-23.

[280] Rudman D, Feller AG, Nagraj HS. Effect of human growth hormone in men over 60 years old. New Engl J Med 1990;323:16.

[281] Miller RA, Chrisp C, Jackson AU, Galecki AT, Burke DT. Coordinated genetic control of neoplastic and nonneoplastic diseases in mice. J Gerontol A Biol Sci Med 2002;5:B3-8.

[282] Sohal RS, Weindruch R. Oxidative stress, calorie restriction, and aging. Science 1996;273:59-63.

[283] Dempsey JL, Pfeiffer M, Morley AA. Effect of dietary restriction on in vivo somatic mutation in mice. Mutat Res 1993;291:141-8.

[284] Stuart GR, Oda Y, de Boer JG, Glickman BW. No change n spontaneous mutation frquency or specificity in dietary restricted mice. Carcinogenesis 2000;21:317-9.

[285] Reiter RJ, Tan DX, Allegra M. Melatonin: reducing molecular pathology and dysfunction due to free radical and associated reactant. Neuroendocrinol Lett 2002;23(Suppl. 1):3-8.

[286] Musatov SA, Anisimov VN, Andre V, Godard F, Sichel F. Modulatory effects of melatonin on genotoxic response of reference mutagens in the Ames test and the COMET assay. Mutat Res 1998;417:75-84.

[287] Vijalaxmi, Meltz ML, Reiter RJ, Herman TS. Melatonin and protection from genetic damage in blood and bone marrow: whole-body irradiation studies in mice. $J$ Pineal Res 1999;27:221-5.

[288] Ubeda A, Trillo MA, House DE, Blackman CF. Melatoninenhances junctional transfer in normal $\mathrm{C} 3 \mathrm{H} / 1 \mathrm{OT} 1 / 2$ cells. Cancer Lett 1995;91:241-5.

[289] Anisimov VN, Khavinson VK, Morozov VG. Twenty years of study on effects of pineal peptide preparation: Epithalamin in experimental gerontology and oncology. Ann New York Acad Sci 1994;719:483-93.

[290] Anisimov VN, Arutjunyan AV, Khavinson VK. Effect of pineal peptide preparation Epithalamin on free radical processes in animals and humans. Neuroendoer Lett 2001;22:9-18.

[291] Thatcher AR, Kannisto V, Vaupel JW. The force of mortality at ages 80-120. Odense: Odense University Press, 1998.

[292] Stenbeck M, Rosen M, Sparen P. Causes of increasing cancer prevaence in Sweden. Lancet 1999;354:1093-4.

[293] von Wangenheim KH, Peterson HP. Control of cell proliferation by progress in differentiation: clues to mechanisms of aging, cancer causation and therapy. J Theor Biol 1998;193:663-78.

[294] Anisimov VN, Soloviev MN. Evolution of concepts in gerontology. St. Petersburg: Aescukip, 1999.

[295] Simons JW. Coming of age:'dysgenetics'-a theory connecting induction of persistent delayed genomic instability with disturbed cellular aging. Int J Radiat Biol 2000;76:1533-43.

[296] Rubin H. Cell damage, aging and transformation: a multilevel analysis of carcinogenesis. Anticancer Res 1999;19:4877-86.

[297] Khavinson VK, Morozov VG, Anisimov VN. Experimental studies of the pineal gland preparation epithalamin. In: Bartsch C, Bartsch H, Blask DE, Cardinali DP, Hrushesky WJM, Mecke
$\mathrm{D}$, editors. The pineal gland and cancer, neuroimmunoendocrine mechanisms in malignancy. Berlin: Springer, 2001:294-306.

[298] Khavinson VK, Izmaylov DM, Obukhova LK, Malinin VV. Effect of epitalon on the lifespan increase in Drosophila melanogaster. Mech Ageing Dev 2000;120:141-9.

[299] Ukraintseva SV, Yashin AT. How individual age-associated changes may influence human morbidity and mortality patterns. Mech Ageing Dev 2001;122:1447-60.

[300] Lee CK, Klopp RC, Weindruch R, Prolla TA. Gene expression profile of aging and its retardation by calorie restriction. Science 1999;285:1390-3.

[301] Lee CK, Weindruch R, Prolla TA. Gene-expression profile of the ageing brain in mice. Nat Genet 2000;25:294-7.

[302] Weindruch R, Kayo T, Lee CK, Prolla TA. Microarray profiling of gene expression in aging and its alteration by calorie restriction in mice. J Nutr 2001;131:918S-23S.

[303] Weindruch R, Kayo T, Lee CK, Prolla TA. Gene expression profiling of aging using DNA microarrays. Mech Ageing Dev 2002;123:177-93.

[304] Welle S. Gene transcript profiling in aging research. Exp Gerontol 2002;37:583-90.

[305] Aragona M, Maisano R, Panetta S, Giudice A, Morelli M, La Torre I, La Torre F. Telomere length maintenance in aging and carcinogenesis. Int J Oncol 2000;17:981-9.

[306] Krupp G, Bonatz G, Parwaresch R. Telomerase, immortality and cancer. Biotechnol Annu Rev 2000;6:103-40.

[307] Reddel RR. The role of senescence and immortalization in carcinogenesis. Carcinogenesis 2000;21:477-84.

\section{Biography}

Professor Vladimir N. Anisimov was graduated from 1st Leningrad Medical Institute (1968), received his Ph.D. (1972) and D.Sc. (1984) degrees from the N.N. Petrov Research Institute of Oncology (St. Petersburg). In 1996, he was elected as an Associate member of the Russian Academy of Natural Sciences. Since 1987, he is Chief, Laboratory of Carcinogenesis and Aging at the Petrov' Institute, and since 1998-also the Head, Department of Carcinogenesis and Oncogerontology at the same institute. Since 1999 he is also Scientific Director, St. Petersburg Institute of Bioregulation and Gerontology, North-Western Branch of the Russian Academy of Medical Sciences. His main scientific interests are relationship between aging and cancer, modifying factors of carcinogenesis, experimental gerontology, the role of pineal gland in cancer and aging. He is a member of a number of scientific societies and of editorial board of several international journals, since 1994 he is the president, the Gerontological Society of the Russian Academy of Sciences. Prof. Anisimov is author and coauthor of 12 monographs, including 'Carcinogenesis and Aging', vol. 1 and 2, CRC Press, Boca Raton, 1987, 'Principles for Evaluating Chemical Effects on the Aged Population, Environmental Health Criteria 144', WHO, Geneva, 1993, and 'Evolution of Concepts in Gerontology', Aesculap, St. Petersburg, 1999, several chapters in books, more than 320 scientific papers in peer-reviewed international and Russian journals. 